\title{
GCU
}

Glasgow Caledonian

University

University for the Common Good

\section{Etifoxine reverses weight gain and alters the colonic bacterial community in a mouse model of obesity}

Ibrahim, Khalid S.; Craft, John A.; Biswas, Lincoln; Spencer, Janice; Shu, Xinhua

Published in:

Biochemical Pharmacology

DOI:

10.1016/j.bcp.2020.114151

Publication date:

2020

Document Version

Author accepted manuscript

Link to publication in ResearchOnline

Citation for published version (Harvard):

Ibrahim, KS, Craft, JA, Biswas, L, Spencer, J \& Shu, X 2020, 'Etifoxine reverses weight gain and alters the colonic bacterial community in a mouse model of obesity', Biochemical Pharmacology, vol. 180, 114151. https://doi.org/10.1016/j.bcp.2020.114151

\section{General rights}

Copyright and moral rights for the publications made accessible in the public portal are retained by the authors and/or other copyright owners and it is a condition of accessing publications that users recognise and abide by the legal requirements associated with these rights.

Take down policy

If you believe that this document breaches copyright please view our takedown policy at https://edshare.gcu.ac.uk/id/eprint/5179 for details

of how to contact us. 


\title{
Biochemical Pharmacology
}

Etifoxine reverses weight gain and alters the colonic bacterial community inEtifoxine reverses weight gain and alters the colonic bacterial community in a mouse model of obesity a mouse model of obesity

\author{
--Manuscript Draft--
}

\begin{tabular}{|c|c|}
\hline Manuscript Number: & BCP-D-20-00767R2 \\
\hline Article Type: & Full Length Articles \\
\hline Section/Category: & Gastrointestinal Pharmacology \\
\hline Keywords: & $\begin{array}{l}\text { Etifoxine; Obesity; weight-loss; colonic microbiome and microbial functionality; } \\
\text { QIIME } 2 \text { \& PICRUSt }\end{array}$ \\
\hline Corresponding Author: & $\begin{array}{l}\text { KHALID S IBRAHIM, Ph.D. } \\
\text { Glasgow Caledonian University Department of Biological and Biomedical Sciences } \\
\text { Glasgow, UNITED KINGDOM }\end{array}$ \\
\hline First Author: & KHALID S IBRAHIM, Ph.D. \\
\hline \multirow[t]{5}{*}{ Order of Authors: } & KHALID S IBRAHIM, Ph.D. \\
\hline & John A Craft, BSc, PhD \\
\hline & Lincoln Biswas, BHMS, MSc, PhD \\
\hline & Janice Spencer, BSc (Hons), PhD \\
\hline & Xinhua Shu, PhD \\
\hline Abstract: & $\begin{array}{l}\text { Obesity is intimately associated with diet and dysbiosis of gut microorganisms but } \\
\text { anxiolytics, widely used in treatment of psychiatric conditions, frequently result in } \\
\text { weight gain and associated metabolic disorders. We are interested in effects of the } \\
\text { anxiolytic Etifoxine, which has not been studied with respect to weight gain or effects } \\
\text { on gut microorganisms. Here we induced obesity in mice by feeding a high-fat diet but } \\
\text { found that intraperitoneal administration of Etifoxine resulted in weight loss and } \\
\text { decreased serum cholesterol and triglycerides. Obese mice had increased hepatic } \\
\text { transcripts associated with lipid metabolism (cyp7a1, cyp27a1, abcg1 and LXRa) and } \\
\text { inflammatory factors (TNFa and IL18) but these effects were reversed after Etifoxine } \\
\text { treatment other than cyp7a1. Taxonomic profiles of the organisms from the caecum } \\
\text { were generated by } 16 \mathrm{~S} \text { rRNA gene sequencing and Obese and Etifoxine mice show } \\
\text { differences by diversity metrics, Differential Abundance and functional metagenomics. } \\
\text { Organisms in genus Oscillospira and genera from Lachnospiraceae family and } \\
\text { Clostridiales order are higher in Control than Obese and at intermediate levels with } \\
\text { Etifoxine treatment. With respect to community metabolic potential, Etifoxine mice have } \\
\text { characteristics similar to Control and particularly with respect to metabolism of } \\
\text { butanoate, sphingolipid, lipid biosynthesis and xenobiotic metabolism. We suggest } \\
\text { mechanisms where-by Etifoxine influences processes of host, such as on bile acid } \\
\text { synthesis, and microbiota, such as signalling from production of butanoate and } \\
\text { sphingosine, resulting in decreased cholesterol, lipids and inflammatory factors. We } \\
\text { speculate that the indirect effect of Etifoxine on microbial composition is mediated by } \\
\text { microbial b-glucuronidases that metabolise excreted Etifoxine glucuronides. }\end{array}$ \\
\hline
\end{tabular}


1 Etifoxine reverses weight gain and alters the colonic bacterial community in a

2 mouse model of obesity

3 Khalid S Ibrahim ${ }^{1,3, *, \#, \text { John A Craft }}{ }^{1, *}$, Lincoln Biswas ${ }^{1}$, Janice Spencer ${ }^{1}$ and Xinhua Shu ${ }^{1,2, \#}$

4

$5 \quad{ }^{1}$ Department of Biological and Biomedical Sciences, Glasgow Caledonian University,

6 Glasgow, UK

$7 \quad{ }^{2}$ Department of Vision Science, Glasgow Caledonian University, Glasgow, UK

$8{ }^{3}$ Department of Biology, Faculty of Science, University of Zakho, Kurdistan Region, Iraq. 9

$10 *$ Joint first authors,

11 Email addresses

12 KS Ibrahim KhalidSubhi.Ibrahim@gcu.ac.uk

$13 \quad$ JA Craft j.a.craft@gcu.ac.uk

14 L Biswas Lincoln.Biswas@gcu.ac.uk

15 J Spencer Janice.Spencer@gcu.ac.uk

16 X Shu Xinhua.Shu@gcu.ac.uk

17 \#Corresponding authors.

18 Khalid S. Ibrahim, Glasgow Caledonian University, Glasgow, G4 0BA, United Kingdom.

19 Tel: +447762060899; E-mail: KhalidSubhi.Ibrahim@gcu.ac.uk : Xinhua Shu, Glasgow

20 Caledonian University, Glasgow G4 0BA, United Kingdom. Tel: 0044141 3318763; Email:

21 Xinhua.Shu@gcu.ac.uk 
Etifoxine reverses weight gain and alters the colonic bacterial community in a mouse model of obesity

\section{Abstract}

Obesity is intimately associated with diet and dysbiosis of gut microorganisms but anxiolytics, widely used in treatment of psychiatric conditions, frequently result in weight gain and associated metabolic disorders. We are interested in effects of the anxiolytic Etifoxine, which has not been studied with respect to weight gain or effects on gut microorganisms. Here we induced obesity in mice by feeding a high-fat diet but found that intraperitoneal administration of Etifoxine resulted in weight loss and decreased serum cholesterol and triglycerides. Obese mice had increased hepatic transcripts associated with lipid metabolism (cyp7a1, cyp27a1, abcg1 and $L X R \alpha$ ) and inflammatory factors (TNF $\alpha$ and IL18) but these effects were reversed after Etifoxine treatment other than cyp7a1. Taxonomic profiles of the organisms from the caecum were generated by 16S rRNA gene sequencing and Obese and Etifoxine mice show differences by diversity metrics, Differential Abundance and functional metagenomics. Organisms in genus Oscillospira and genera from Lachnospiraceae family and Clostridiales order are higher in Control than Obese and at intermediate levels with Etifoxine treatment. With respect to community metabolic potential, Etifoxine mice have characteristics similar to Control and particularly with respect to metabolism of butanoate, sphingolipid, lipid biosynthesis and xenobiotic metabolism. We suggest mechanisms whereby Etifoxine influences processes of host, such as on bile acid synthesis, and microbiota, such as signalling from production of butanoate and sphingosine, resulting in decreased cholesterol, lipids and inflammatory factors. We speculate that the indirect effect of Etifoxine on microbial composition is mediated by microbial $\beta$-glucuronidases that metabolise excreted Etifoxine glucuronides.

Keywords: Etifoxine; Obesity; weight-loss; colonic microbiome colonic microbial functionality; QIIME 2; PICRUSt 


\section{Introduction}

The use of many antipsychotic drugs is compromised by side-effects of obesity [1] and associated metabolic syndromes resulting in increased morbidity and mortality [2]. Obesity and associated metabolic disorders are a global health concern and causes of obesity are complex, but it is widely accepted that diets rich in fat and meat-derived proteins, typical of the Western hemisphere, are a major cause [3]. Indeed, the large surges in obesity in many developing countries seen in recent decades can be attributed to a shift from a vegetable-rich diet to a more Western-style diet. Appetite and food intake are under complex genetic control involving the interaction of hormones responding to dietary metabolites, neuro-endocrines and gut-produced incretins and Western-style diets appear to be able to over-ride these controls $[4,5]$. The reasons why antipsychotics cause obesity are largely unknown and here we investigate the effects of etifoxine, an antipsychotic that has not previously been assessed in this respect.

\section{Obesity is associated with dramatic changes of the gut microbiota from communities typical}

of the lean state [7]. Animals are host to complex communities of microorganisms in the gut

\section{that play a symbiotic role in well-being in which reciprocal signalling between host and}

microbiome are significant [6]. It is postulated that bacterial dysbiosis results in alterations of the two-way provision and nature of signalling between host and bacteria. Increased production of energy-producing products, of inflammatory products and of bacterial toxins along with decreased production of mucin-producing stimulants are significant in the onset of obesity [8]. An example of two-way signalling is provided by bile acids which are interrelated to host cholesterol homeostasis. Excess cholesterol is converted to primary bile acids in the liver and these may be converted by gut bacteria to secondary bile acids. In the liver of mice, bile acid synthesis is initiated principally by cyp7a1 but also by mitochondrial cyp27a1 
74 duodenum upon eating. Secondary bile acids are then formed by microbial de-conjugation in

75 the small intestine and colon. Secondary bile acids regulate expression of host enzymes

76 catalysing rate-limiting steps of cholesterol conversion to bile acids $[9,10]$ and influence the 77 host immune function and regulate gut bacterial composition [11-13]. With respect to 78 cholesterol metabolism, etifoxine acts on the host via the mitochondrial transmembrane 79 translocator (TSPO) to increase cholesterol trafficking and provides protection against 80 oxidative stress, inflammation and cholesterol accumulation [14].

Here we describe the results of studies of obesity, induced by a high-fat diet, on host and microbiome systems and on the consequences of etifoxine co-administration. A major focus for studies of obesity and altered microbiome has been food composition and to the best of our knowledge, the effects of drugs (other than antibiotics) have not been a major consideration. We postulated that etifoxine would reverse weight gain and increased serum lipids resulting from the diet and that potential effects of etifoxine on gut microbiome composition would have beneficial effects through microbial signalling that interacts with host regulatory systems. These expectations were realised and we present data suggesting a 
variety of mechanisms by which etifoxine affects gut microbial communities and microbial

99 signalling that results in weight loss and beneficial effects on the host.

\section{Materials and Methods}

\subsection{Animal Husbandry}

The animals used for this study were housed in the Animal Care Unit of the University of Strathclyde, according to the UK Home Office Animal Care regulations and the experimental procedures were authorised by the University of Strathclyde Animal Welfare Authority (Project licence P8C815DC9). C57BL/6 male mice (body weight, 20-25g at the start of the experiment) were used. The mice were randomly divided into three experimental groups, 6 animals per group; two groups were fed with a high-fat diet (HFD, Crude fat 22.3\%, Crude protein 19.9\%, Crude fibre 3.8\%, Ash 5.1\%, Carbohydrate 41.1\% (w/w); provided by Special Diet Services, UK) while the third group was fed with a standard chow diet (7\% simple sugars, 3\% fat, 50\% polysaccharide, 15\% protein (w/w) (Special Diet Services, UK).

After 13 weeks, one group of HFD-fed mice were treated daily with etifoxine (50mg/kg), i.p. and the other two groups were treated with $0.1 \%$ Tween-80 in saline solution (vehicle of etifoxine) for 15 days after which the mice were sacrificed by anaesthesia $\left(\mathrm{CO}_{2}\right)$ and serum and liver collected. Note that the dosage used here is at the low end of that used in human treatment $[17,18]$. Luminal samples were extracted from the colon adjacent to the caecum and then frozen in dry ice and stored at $-80^{\circ} \mathrm{C}$ until used.

\subsection{Bacterial DNA isolation}

Genomic DNA was isolated from the colonic samples within one day of collection using the QIAamp DNA Stool Mini Kit (QIAGEN Manchester Limited (UK) following the manufacturer's protocol. Separate isolations were made from individual faecal material (50$150 \mathrm{mg}$ )/animal, then placed in a $2 \mathrm{~mL}$ Lysing Matrix E (1.4 ceramic spheres, $0.1 \mathrm{~mm}$ silica 
122 spheres and one $4 \mathrm{~mm}$ glass bead) microcentrifuge tubes (MP Biochemicals, Strasbourg,

France). Tube contents were thoroughly homogenized in ASL Buffer using a FastPrep ${ }^{\circledR}-24$ Instrument (MP Biomedicals, UK) at $4.5 \mathrm{M}$ second-1 for 60 seconds and homogenization repeated after a rest of 5 mins on ice. A single DNA sample for each individual animal was recovered and stored at $-80^{\circ} \mathrm{C}$ prior to sequencing.

\subsection{Serum lipids}

Serum lipids were extracted by the manufacturers' protocols. The total cholesterol was assessed by Amplex Red Cholesterol Assay kit (Thermo Fisher, UK), according to the previous publications [19]. For triglyceride concentration determination the sera were examined with the EnzyChrom Triglyceride assay kit (BioAssay System, UK).

\subsection{Hepatic Gene expression}

The isolation of total RNA and subsequent cDNA synthesis were as described 134 previously [19] Gene expression was quantified by quantitative real-time polymerase chain 135 reaction (qRT-PCR) using a 5x HOT FIREPol® EvaGreen ${ }^{\circledR}$ qPCR Supermix (Newmarket 136 Scientific, UK) according to the manufacturer's protocols. Briefly, the Ct value was 137 quantified with the Bio-Rad CFX96 Real-Time PCR Detection System (Bio-Rad, UK) under 138 the following conditions: $50^{\circ} \mathrm{C}$ for $2 \mathrm{~min}$ (UDG incubation) followed by an enzyme activation 139 step at $95^{\circ} \mathrm{C}$ for 2 min and amplification for 40 cycles including DNA denaturation at $95^{\circ} \mathrm{C}$ 140 for 15 seconds and primer annealing at $60^{\circ} \mathrm{C}$ for 15 seconds and elongation for 20 seconds. 141 The relative mRNA expression was analysed by $2^{-\Delta \Delta C T}[20]$ and was normalised with the $\beta$ 142 actin housekeeping gene. Primer sequences are shown in Table 1. 


\subsection{S rRNA gene library production and sequencing}

Purified DNA from each animal was used for PCR amplification and sequencing of 16S rRNA genes on an Illumina MiSeq instrument with 2 x 300 base-pair paired-end reads at LGC Genomics, Germany. Universal primers of 16S rRNA genes were used to amplify the hypervariable regions, V3-V5 (V3F (341F), V5R (785R)) [21]. In a second PCR, Illumina TruSeq adapters and tag index sequences were attached prior to sequencing. Reads were demultiplexed at LGC and basic statistics are shown in Table 2. All reads were reported as fastq along with fastqc files showing phred values $>20$. Reads and metadata have been submitted to the SRA with Accession Number PRJNA596121.

\subsection{Data analysis with QIIME2 and PICRUST}

Data processing, quality trimming, taxonomic classification, diversity and differential abundance were analysed with modules (plugIns) in QIIME2-2018.8 (https://qiime2.org; https://peerj.com/preprints/27295/) [22]. QIIME2 is a microbiome-analysis pipeline that incorporates many previous stand-alone facilities with facilities developed by the QIIME2 team. Demultiplexed reads were imported using the Fastq manifest protocol (import is directed by a tab-separated text file) (https://docs.qiime2.org/2019.1/tutorials/importing/) prior to an additional layer of quality filtering using DADA2 (settings p-trim-left $10 \mathrm{bp}$ and ptrim-right 240) [23]. DADA2 truncates reads at both ends to the specified length, joins the reads and removes any chimeric sequences. Taxonomy was assigned to features using a classifier trained with the QIIME2 plugin [24] using the Greengenes data base (v 13.8) set at 99\% sequence identity [25]. Diversity of the microbial communities were assessed using 164 several methods available in the q2-diversity plugin (see https://forum.qiime2.org/t/alpha-and165 beta-diversity-explanations-and-commands/2282 for original citations). Differential 166 Abundance was determined using gneiss and Linked Taxonomy was generated with p-taxa- 
167 level set to 5 (https://docs.qiime2.org/2019.7/tutorials/gneiss/). This approach seeks to

identify groups of taxa (balances or proportions) that co-segregate under various experimental conditions and thus which balance might change with those conditions. Co-segregation is identified using correlation with unsupervised Ward's hierarchical clustering to obtain Principal Balances.

The frequency and taxonomic data were processed in QIIME2 for closed-reference clustering with vsearch [26] with identity set at 0.99 and using the trained classifier produced earlier.

The table produced was exported for further analysis in PICRUSt [27] for metagenomic function imputation. PICRUSt allows predictions to be made for the presence of genes even in un-sequenced taxa by the construction of phylogenetic trees and inference when sufficient genome sequences are available from close family members. These predictions apply to both enzyme-encoding genes and 16S rRNA genes allowing normalization to 16S gene copy number. Metagenome predictions were collapsed to KEGG-Pathways with level set to 3. The metagenome predictions were also used to compute the contribution of individual taxa to chosen KEGG orthologue enzymes.

Results were obtained using the ARCHIE-WeSt High Performance Computer (www.archie-west.ac.uk) based at the University of Strathclyde.

\subsection{Statistics}

Data is presented as mean +/- SEM and differences within and between groups were assessed using GraphPad Prism Software (version 8.02, 441, Inc., San Diego, CA, USA). Data distribution was tested by selecting in Prism the methods of Anderson-Darling, D'Agostino \& Pearson, Shapiro-Wilk test and Kolmogorov-Smirnov (alpha=0.05) and normality was only accepted if all methods agreed. Data was analysed by One-way ANOVA 
191 with Tukey's post-hoc test, if the data had a normal distribution while the Kruskal Wallis test

followed by Dunn's multiple comparisons test was used if data was nonparametric. Other

statistical tests are built into the QIIME2 Plugins. A p value of $<0.05$ was considered significant.

\section{Results}

\subsection{Effects on the host as measured by lipids in serum and hepatic qRT-PCR data}

It was expected that the high-fat diet would have direct effects on animal metabolism

and we investigated this and the effects of etifoxine by measurement of serum cholesterol and triglycerides. Administration of the high fat diet increased serum levels of both cholesterol (Figure 1c) and triglycerides (Figure 1d). However, administration of etifoxine produced significant reductions of these lipids close to those observed in the Control animals.

In addition to lipid analytes, relative levels of liver mRNAs associated with lipid processing were also determined. These included cyp7a1, cyp27a1, abcg1, abca1, and LXRa. Figure 1e 
215 shows that the relative level of cyp7a1, cyp27a1, abcg1 and $L X R \alpha$ were elevated in HFD

mice. Cyp7a1 remained elevated in HFD+E but cyp27a1, abcg1 and $L X R \alpha$ declined to values intermediate between the HFD and Control animals. No statistically significant differences were found for expression levels of abca1 between any of the groups. Obesity is associated with an inflammatory state so relative levels of mRNAs for pro-inflammatory TNF $\alpha$, IL-1 $\beta$ and IL-18 were also determined. The high-fat diet elevated levels of TNF $\alpha$ and IL-18, but not IL-1 $\beta$, relative to CD and this was reversed in HFD+E mice for IL-18 and TNF $\alpha$ (Figure 1f).

\subsection{Sequence analysis of bacterial DNA}

After demultiplexing and removal of adaptor and primer sequences, a total of $1.79 \mathrm{M}$, 16S rRNA gene read-pairs (Table 2) were imported to QIIME 2. Subsequent quality-trimming and read-pair joining generated 766,169 reads and 1925 representative rep-seqs were selected with average read length 388.7 base pairs. Subsequent phylogenetic assignment of features produced 103 distinct taxa with $86 \%$ identified at family level, 50\% at genus and 23\% at species level.

\subsection{Phylogenetic composition and the abundance of taxa of the microbiome communities}

Determination of the 16S rRNA gene sequences allowed phylogenetic classification via QIIME 2 of features of the gut microbiota from the level of phylum to species.

The abundance and composition of gut bacteria differs between the three experimental groups and is shown in Figure 2 and Figure 2a shows the abundance of bacteria at the level of phylum. The ratio of Firmicutes/ Bacteroides is elevated in HFD v CD but there is a distinct shift back towards CD in this value in HFD+E (Figure 2b). In greater detail changes relative to CD can be seen in HFD and these appear to be reversed towards CD in HFD+E. For instance, in the Control animals (CD), the most abundant bacteria were unclassified species of 
family Lachnospiraceae, order Clostridiales and family S24-7. The abundance of these

organisms is decreased in HFD but increased towards CD in HFD+E (Figure 2c). Conversely, Allobaculum and unclassified genera of order Clostridiales are increased in HFD vs CD but less so in HFD+E.

Differences in the diversity of taxa across the groups were investigated by measures of both $\alpha$ - and $\beta$-diversity. For $\alpha$-diversity observed_otus and chao1 showed clear differences of HFD compared with both $\mathrm{CD}$ and HFD+E while no significant differences were found between CD and HFD+E (Figure 3a \& b, respectively). Additionally, correlation analysis based on animal weight and the vector of alpha diversity, using the Spearman method, indicated a significant difference (observed_otus and chao1; test statistic $=0.6599, \mathrm{p}=0.0029, \mathrm{n}=18$ ). Figures $3 \mathrm{c}$ and $\mathrm{d}$ show differences of $\beta$-diversity in bacterial communities between groups were conducted by 3D PCoA Emperor Plots with Bray Curtis and weighted unifrac metrics. The results of these analyses reveal spatial separation between the Control (CD) and both groups of the high-fat animals (HFD and HFD+E). However, some separation between HFD and HFD+E groups was apparent and it appears that HFD+E is approaching values seen in CD.

\subsection{Differential Abundance of taxa based on balances metrics}

Ward's hierarchical clustering was used to define the log ratios of microbes that are found together under defined conditions, here the experimental treatment of each group of animals. The statistics produced can be used to guide the choice of subsets of interest. Using this approach, and one such balance with 737 taxa in the numerator and 63 in the denominator produced a much lower log2 ratio in HFD than CD while an intermediate value was found for

HFD+E (Figure 3e). Organisms in Clostridiales, Lachnospiraceae, Lactobacillus and

Oscillospira appear to be significant (Figure 3f). 


\subsection{Derivation of the functional microbiome using PICRUSt}

The potential for bacterial metabolism in each bacterial group has been provided by PICRUSt. The normalised data was analysed by Kyoto Encyclopaedia of Genes and Genomes (KEGG) Pathway at level 3 and significant differences were identified as illustrated in Figure 4. Pair-wise comparison indicated 39 pathways with differences between at least two groups. Significant differences ( $\mathrm{p}<0.05$ ) between HFD and HFD+E were found in 27/39 pathways. When comparing CD to HFD+E, 24 of those 27 pathways showed no difference i.e. these pathways approach levels seen in the Control. When comparing CD to HFD, differences were seen in 39/39 pathways.

So as to focus on major metabolic functional activities, a deeper analysis of some significant pathways was done at the level of individual enzymes present in taxa in those pathways using the 'metagenomics_contributions' script. These included butanoate metabolism, sphingolipid metabolism, synthesis and degradation of ketone bodies, and drug metabolism-other enzymes. Additionally, production of bacterial virulence factors were also analysed.

The short-chain fatty acid, butanoate plays an important role in gut function and health and therefore its metabolism was analysed in detail. In butanoate metabolism (Figure 5a, PATH: ko00650), 4 orthologous enzymes were imputed to be significantly higher in CD and HFD+E vs HFD and two of these have a direct role in butanoate formation, namely K00929 (butyrate kinase [EC:2.7.2.7]) (Figure 5b) and K00634 (phosphate butyryl-transferase [EC:2.3.1.19]) (Figure 5c). Only two enzymes (K00241) and (K7250) were significantly higher in CD vs HFD alone while HFD+E was higher than HFD but not significantly so. Three enzymes were higher in HFD alone vs CD while one was higher in HFD vs CD and HFD+E. All of the 
enzymes where HFD was greater than CD are concerned with acetoin and acetoacetate metabolism.

In the lipid metabolic pathways (Figure 6a) the imputed synthesis of ketone bodies [PATH: ko00072] was lower in CD and HFD+E compared to HFD while sphingolipid metabolism [PATH: ko00600] was higher in CD and HFD+E compared to HFD. In addition, lipid biosynthesis proteins [PATH: ko01004] and Steroid hormone biosynthesis [PATH:ko00140] were higher in CD compared to HFD whereas Linoleic acid metabolism [PATH:ko00591] was lower in CD compared to HFD. Imputed activity levels of individual enzymes in the ketone body pathway are shown in Figure 6b. Two enzymes of the ketone body pathway were significantly enriched in HFD vs both CD and HFD+E including hydroxy-methyl-glutarylCoA synthase that catalyses the rate-limiting step of cholesterol biosynthesis. In sphingolipid metabolism, metabolic contributions from 7 enzymes would, potentially, be higher in CD and HFD+E vs HFD and different bacteria were associated with these changes (Figure 7). All of these enzymes are involved in the conversion of glucosylceramide and galactosylceramide to ceramide ( $\mathrm{N}$-acylsphingosine), the primary precursor of sphingosine.

Bacteria can produce virulence factors which have effects on host cells and restrict the immune system. Figure 8a shows analysis of pathways leading to the production of bacterial toxins (cfa; cAMP factor; tcdAB; toxin A/B from Clostridioides difficile) where production is higher in HFD compared to both CD and HFD+E. Conversely hya; hyaluronoglucosaminidase was found to be significantly lower in HFD vs both CD and 309 HFD+E. Figure 8b shows enzymes involved in bacterial invasion of epithelial cells 310 [PATH:ko05100] and found 3 activities (fnbB; fibronectin-binding protein B , sfb1; 311 fibronectin-binding protein 1 and yeeJ; adhesion factors) significantly higher in HFD vs CD 
312 and vs HFD+E. With respect to the endotoxin LPS, 3 enzymes involved in metabolism of

lipid A (K12973, K12974 and K02560) and 2 involved in metabolism of the O-antigen (K02847 and K02851) were elevated in HFD compared to CD and HFD+E while 3 enzymes of O-antigen metabolism (K12990, K132002 and K13004) were diminished in HFD but were higher in CD and HFD+E. Data for K12973, K02560 and K12990 are shown in Figure 8c; others involved with LPS metabolism, data not shown.

Although the bile acid-related pathways were not significantly different between groups, the important role of these pathways in cholesterol homeostasis and recycling and their influence on inflammatory processes had obvious relevance to our investigation. In secondary bile acid biosynthesis [PATH:ko00121], 7-alpha-hydroxysteroid dehydrogenase [EC:1.1.1.159] (K00076) was significantly higher in HFD than CD while 3-dehydro-bile-acid Delta-4,6dehydrogenase (baiN; K07007) was higher in HFD+E than HFD (Figure 8d).

In other bacterial metabolism, enzymes involved in drug metabolism - other enzymes [PATH:ko00983] were considered. Imputed metabolic contributions from 4 enzymes were significantly higher in CD and HFD+E vs HFD and different bacteria were involved for these changes (Figure 9a). The role of beta-glucuronidase [EC:3.2.1.31] (uidA, GUSB; K01195) is considered to be important (Figure 9b) and is discussed below.

\section{Discussion}

\subsection{Antipsychotics, weight and bacterial colonic communities}

Here we find that etifoxine, an antipsychotic, is able to reverse weight gain induced by a highfat diet and this property is unlike the majority of antipsychotic drugs that cause weight gain $[1,2]$. While the treated mice have lost a significant amount of weight, they are still 
technically obese with respect to weight. Diets high in fat cause changes of intermediary metabolism, adipose deposition and inflammation [28] and changes in gut microbiota that contributes towards the obese state [29-32]. Changes in community structure in the obese mice were detected by alterations of diversity metrics and these were altered by etifoxine treatment to give values between the HFD and Control groups. The taxonomic profiles of the Control, Obese and Etifoxine groups show distinct differences but detecting changes in abundance of individual taxa in complex bacterial communities is difficult and cannot be reliably determined by simple relative abundance. However, it has been suggested that such problems can be overcome by seeking subsets of taxa that are co-associated with an experimental parameter and employing the idea of proportions or 'balances' [33]. Using the Differential Abundance module in QIIME 2, differences between all three groups were found providing further evidence that the etifoxine administration was able to influence bacterial community structure. Thus log differences between values of the abundance ratio between each group indicate that taxa in the denominator species-set must be more abundant in the HFD than HFD+E in which they must be more abundant than in Control. Alternatively the numerator species-set must be in the order Control > HFD+E > HFD.

\subsection{Serum cholesterol and TGs}

Cholesterol was diminished to control levels in the blood plasma of the HFD+E animals. One target of etifoxine action is TSPO, in the outer mitochondrial membrane, and that stimulates cholesterol transit. This would allow an elevation of cholesterol metabolism to bile acids via the mitochondrial cyp27a1. Obesity is associated with mitochondrial disruption and a block of the differentiation of preadipocytes, processes which can be reversed by TSPO activators. PK 11195 and Ro5-4864 are other TSPO activators and elicit in adipose differentiation of preadipocytes [14] with improved glucose regulation and weight loss in obese mice [14,34]. 
Etifoxine binds to the same site on TSPO as Ro5-4864 [35] so we assume its activity in our model operates in the same way. Etifoxine has also been shown to affect insulin signalling molecules by exacerbating insulin resistance but reversing lipid accumulation caused by infection with Hepatitis C-related virus [36]. The safety of etifoxine for therapeutic use has long, been questioned and was recently high-lighted by a French retrospective study identifying a number of adverse effects including hepatitis in some cases [18].

Both $a b c a 1$ and $a b c g 1$ are responsible for cholesterol efflux in reverse cholesterol transport (RCT), which moves excess cholesterol from peripheral tissues via the plasma to the liver, where cholesterol can be directly released into the bile or be metabolised into bile acids by cyp7a1 and cyp27a1 [37]. Previous work shows that TSPO ligands promote cholesterol efflux in macrophages, retinal pigment epithelial and choroidal endothelial cells and upregulated expression of RCT component genes [19,38,39]. However, the effect of the TSPO ligand, Etifoxine on expression of RCT genes in liver was different from that seen in peripheral tissues including macrophage and retinal cells, possibly because the liver is the main cholesterol-synthesizing tissue in the body. Our earlier work demonstrates that Etifoxine suppresses oxidized LDL-induced inflammation by decreasing the secretion of proinflammatory cytokines [39]. Here we also found decreased levels of hepatic transcripts for proinflammatory cytokines, TNF $\alpha$ and IL-18.

380 Treatment with etifoxine appears to have signalled an alteration of the gut microbiome and 381 changes of composition of gut bacterial taxa will have important consequences on metabolic potential. Bacteria of the gut microbiome interact with each other and the host through small molecules produced as end-products of metabolic pathways. We have found a number of such 
signallers that potentially would influence the metabolism of cholesterol and inflammatory

385 factors.

387 Butanoate is one such product and has a crucial role in colonic epithelial cells by supplying an energy source and increasing cell proliferation. Here imputed butanoate production is increased in HFD+E, from a low level in HFD, to levels similar to those of CD. Butanoateproducing bacteria such as unidentified taxa from Clostridiales order and families of Lachnospiraceae, Peptostreptococcaceae, Ruminococcaceae and S24-7 are increased after etifoxine treatment. One of the benefits of butanoate is to protect the host through increased mucin production that maintains the intestinal mucosal surface as a protective intestinal barrier [40,41] from pathogenic organisms and inflammatory bacterial products [42] and by enhancing tight junction integrity in response to injury. Other benefits of butanoate include inhibition of the production of proinflammatory cytokines [40,41] and inhibition of the synthesis of cholesterol by colonocytes [43] [44]. 405 sphingosine-1-phosphate [45].

407 In common with others [3], we find that the high-fat diet of the HFD group increases the 408 imputed production of bacterial virulence factors including toxins, invasion factors and LPS

Another imputed signalling molecule influenced by etifoxine is sphingolipid. Seven KEGG orthologous enzymes were imputed to be significantly higher in CD and HFD+E vs HFD and different bacteria were involved in these changes (Figure 7). Each of these enzymes is involved in the conversion of glucosylceramide and galactosylceramide to ceramide $(\mathrm{N}$ acylsphingosine) the main precursor of sphingosine. Recent work has demonstrated a sphingolipid-responsive colonic GPC receptor, S1PR4, whose endogenous ligand is 
while these effects are reversed or partially reversed in the HFD+E group. Decreased

abundance of commensal organisms in HFD animals would provide opportunities for colonisation by other potentially pathogenic organisms and indeed obesity has been linked to the risk of developing $C$. difficile infection $[47,48]$. In general the production of the virulence 413 factors were elevated in the HFD group such as the bacterial exotoxin cAMP-factor, 414 associated with obesity-driven production of interleukin IL-1 $\beta[49,50]$ and release of 415 proinflammatory cytokines [51]. An increase in the production of toxin A and B from C. 416 difficile is also noted in the HFD group (K11063). This species is a member of the 417 Peptostreptococcaceae family and an increase of abundance of unclassified species of 418 Peptostreptococcaceae result in endothelial dysfunction in obese children and cause the 419 secretion of interleukin (IL-1) and TNF- $\alpha$ [52,53]. A number of imputed activities associated 420 with invasion of epithelial cells (K13735) were also elevated in HFD but decreased in 421 etifoxine-treated animals. Pelagibacteraceae and Enterobacteriaceae produce adhesin/ 422 invasin (yeeJ; K13735), the adhesion factor in E. coli that contributes to colonisation and the 423 promotion of biofilm formation [54] and the increased presence of this gene in the HFD group 424 further supports the view that this diet may support colonisation with pathogenic bacterial 425 species. Here we also find an increase in the capacity of the bacterial community of the Obese 426 to modify LPS and this effect is reversed by etifoxine. On the other hand decreased 427 rhamnosyltransferase in HFD vs both HFD+E and CD may contribute to inflammation. The 428 product of this enzyme is involved in quorum sensing that provides cell-cell communication 429 within species of bacteria and between different genera [55] and preserves commensal 430 bacteria and resistance to infectious diseases in the GI [56]. 

3 4

Few studies have investigated the effects of drugs on gut microbiota other than by direct dietary provision [57-59] but here we find that bacterial communities are affected by the i.p. administration of etifoxine and metabolic functional potential would be altered raising the question of the mechanism behind this effect.

We had expected to discover the significant interplay between cholesterol metabolism in the host with bile acids in the gut since these influence the composition of gut bacterial communities [60]. Although distinctions were found between groups and some KEGG orthologous enzymes, there was no difference at the pathway level. Another possible explanation of the indirect effect on gut microbiota is that metabolites of etifoxine influence the communities. Etifoxine is metabolised in the liver by de-ethylation, oxidation and subsequent glucuronidation [61]. It is likely that the action of bacterial $\beta$-glucuronidase will release glucuronide and an etifoxine metabolite (desethyl hydroxyl etifoxine). Either may play a role in reshaping the bacterial communities by the provision of an energy source and by unknown signalling from the aglycone. Significantly with regard to these suggestions imputed $\beta$-glucuronidase activity was found to be lower in HFD than in CD or HFD+E and taxa of Clostridiales and Lachnospiraceae appear to make a higher contribution to these activities. The importance of bacterial $\beta$-glucuronidase action in weight loss has been previously referred to [62].

In Conclusion, etifoxine reverses weight gain in a mouse model of obesity and effects on host and gut microbiota contribute to this as would be, imputed, improved lipid metabolism and decreased production of virulence factors. In our model obesity was associated with decreased signalling to the gut by butanoate and sphingolipids but increased production of inflammatory agents and lipids usable for host metabolism. We propose that signalling from host to bacteria is mediated in part by etifoxine glucuronide which is a 
substrate for bacterial glucuronidases and which provides an energy source for differential bacterial replication.

\section{Acknowledgement}

We thank Dr Richard Martin and his team at Archie-West for installation and guidance in the use of QIIME2 and PICRUSt.

\section{Funding}

This project was funded by the Rosetrees Trust and National Eye Research Centre.

\section{Author's contributions}

XS designed the study; LB and KSI conducted the experiments; JAC conducted the bioinformatics; JAC, LB and KSI analysed the data and wrote the manuscript; XS, KSI, JS and JAC reviewed the manuscript.

\section{Declarations}

Ethical approval Experiments were conducted under the UK Home Office Animal Care regulations and the experimental procedures were authorised by the University of Strathclyde Animal Welfare Authority (Project licence P8C815DC9).

Consent for publication. The document does not contain any personalized images or information 473 Data availability

474 Sequence data with associated metadata is available at SRA (https://www.ncbi.nlm.nih.gov/sra) PRJNA596121. All of the scripts used are publically available at QIIME2 (https://qiime2.org/), at PICRUSt (http://picrust.github.io/picrust/) and through publications cited here. Any other aspect of the data or analysis resulting from the current study that are not shown will be made available by the corresponding author on reasonable request. 
479 Disclosure of Potential Conflicts of Interest

1

2480 No potential conflicts of interest were disclosed.

3

4

5

6

7

8

9

10

11

12

13

14

15

16

17

18

19

20

21

22

23

24

25

26

27

28

29

30

31

32

33

34

35

36

37

38

39

40

41

42

43

44

45

46

47

48

49

50

51

52

53

54

55

56

57

58

59

60

61

62

63

64

65 


\section{References}

[1] M. Bak, A. Fransen, J. Janssen, J. Van Os, M. Drukker, Almost all antipsychotics result in weight gain: A meta-analysis, PLoS One. (2014). https://doi.org/10.1371/journal.pone.0094112.

[2] D. Arterburn, G.C. Wood, M.K. Theis, E.O. Westbrook, J. Anau, M. Rukstalis, J.A. Boscarino, Z. Daar, G.S. Gerhard, Antipsychotic medications and extreme weight gain in two health systems, Obes. Res. Clin. Pract. (2016). https://doi.org/10.1016/j.orcp.2015.08.012.

[3] M.K. Zinöcker, I.A. Lindseth, The western diet-microbiome-host interaction and its role in metabolic disease, Nutrients. (2018). https://doi.org/10.3390/nu10030365.

[4] J.F. Rehfeld, The origin and understanding of the incretin concept, Front. Endocrinol. (Lausanne). (2018). https://doi.org/10.3389/fendo.2018.00387.

[5] M. Camilleri, Gastrointestinal hormones and regulation of gastric emptying, Curr. Opin. Endocrinol. Diabetes Obes. (2019). https://doi.org/10.1097/MED.0000000000000448.

[6] K.R. Foster, J. Schluter, K.Z. Coyte, S. Rakoff-Nahoum, The evolution of the host microbiome as an ecosystem on a leash, Nature. (2017). https://doi.org/10.1038/nature23292.

[7] M. Aguirre, K. Venema, Does the Gut Microbiota Contribute to Obesity? Going beyond the Gut Feeling, Microorganisms. (2015). https://doi.org/10.3390/microorganisms3020213.

[8] A. Woting, M. Blaut, The intestinal microbiota in metabolic disease, Nutrients. (2016). https://doi.org/10.3390/nu8040202.

[9] S.I. Sayin, A. Wahlström, J. Felin, S. Jäntti, H.U. Marschall, K. Bamberg, B. Angelin, T. Hyötyläinen, M. Orešič, F. Bäckhed, Gut microbiota regulates bile acid metabolism by reducing the levels of tauro-beta-muricholic acid, a naturally occurring FXR antagonist, Cell Metab. (2013). https://doi.org/10.1016/j.cmet.2013.01.003.

[10] A. Wahlström, S.I. Sayin, H.U. Marschall, F. Bäckhed, Intestinal Crosstalk between Bile Acids and Microbiota and Its Impact on Host Metabolism, Cell Metab. (2016). https://doi.org/10.1016/j.cmet.2016.05.005.

[11] A.S. Devlin, M.A. Fischbach, A biosynthetic pathway for a prominent class of microbiotaderived bile acids, Nat. Chem. Biol. (2015). https://doi.org/10.1038/nchembio.1864.

[12] L.A. David, C.F. Maurice, R.N. Carmody, D.B. Gootenberg, J.E. Button, B.E. Wolfe, A. V. Ling, A.S. Devlin, Y. Varma, M.A. Fischbach, S.B. Biddinger, R.J. Dutton, P.J. Turnbaugh, Diet rapidly and reproducibly alters the human gut microbiome, Nature. (2014). https://doi.org/10.1038/nature12820. 
[13] G.D. Wu, J. Chen, C. Hoffmann, K. Bittinger, Y.Y. Chen, S.A. Keilbaugh, M. Bewtra, D. Knights, W.A. Walters, R. Knight, R. Sinha, E. Gilroy, K. Gupta, R. Baldassano, L. Nessel, H. Li, F.D. Bushman, J.D. Lewis, Linking long-term dietary patterns with gut microbial enterotypes, Science (80-. ). (2011). https://doi.org/10.1126/science.1208344.

[14] J. Li, V. Papadopoulos, Translocator protein (18 kDa) as a pharmacological target in adipocytes to regulate glucose homeostasis, Biochem. Pharmacol. (2015). https://doi.org/10.1016/j.bcp.2015.06.020.

[15] C.J. Omiecinski, J.P. Vanden Heuvel, G.H. Perdew, J.M. Peters, Xenobiotic metabolism, disposition, and regulation by receptors: From biochemical phenomenon to predictors of major toxicities, Toxicol. Sci. (2011). https://doi.org/10.1093/toxsci/kfq338.

[16] F.J. Gonzalez, Z.Z. Fang, X. Ma, Transgenic mice and metabolomics for study of hepatic xenobiotic metabolism and toxicity, Expert Opin. Drug Metab. Toxicol. (2015). https://doi.org/10.1517/17425255.2015.1032245.

[17] Y.M. Choi, K.H. Kim, Etifoxine for pain patients with anxiety, Korean J. Pain. (2015). https://doi.org/10.3344/kjp.2015.28.1.4.

[18] J. Cottin, A. Gouraud, M.J. Jean-Pastor, A. Disson-Dautriche, C. Boulay, H. Geniaux, M. Auffret, N. Bernard, J. Descotes, T. Vial, Safety profile of etifoxine: A French pharmacovigilance survey, Fundam. Clin. Pharmacol. (2016). https://doi.org/10.1111/fcp.12169.

[19] L. Biswas, X. Zhou, B. Dhillon, A. Graham, X. Shu, Retinal pigment epithelium cholesterol efflux mediated by the $18 \mathrm{kDa}$ translocator protein, TSPO, a potential target for treating agerelated macular degeneration, Hum. Mol. Genet. (2017). https://doi.org/10.1093/hmg/ddx319.

[20] K.J. Livak, T.D. Schmittgen, Analysis of relative gene expression data using real-time quantitative PCR and the 2- $\Delta \Delta \mathrm{CT}$ method, Methods. (2001). https://doi.org/10.1006/meth.2001.1262.

[21] A. Klindworth, E. Pruesse, T. Schweer, J. Peplies, C. Quast, M. Horn, F.O. Glöckner, Evaluation of general 16S ribosomal RNA gene PCR primers for classical and next-generation sequencing-based diversity studies, Nucleic Acids Res. (2013). https://doi.org/10.1093/nar/gks808.

[22] E. Bolyen, J.R. Rideout, M.R. Dillon, N.A. Bokulich, C.C. Abnet, G.A. Al-Ghalith, H. Alexander, E.J. Alm, M. Arumugam, F. Asnicar, Y. Bai, J.E. Bisanz, K. Bittinger, A. Brejnrod, C.J. Brislawn, C.T. Brown, B.J. Callahan, A.M. Caraballo-Rodríguez, J. Chase, E.K. Cope, R. Da Silva, C. Diener, P.C. Dorrestein, G.M. Douglas, D.M. Durall, C. Duvallet, C.F. Edwardson, M. Ernst, M. Estaki, J. Fouquier, J.M. Gauglitz, S.M. Gibbons, D.L. Gibson, A. 
Gonzalez, K. Gorlick, J. Guo, B. Hillmann, S. Holmes, H. Holste, C. Huttenhower, G.A.

Huttley, S. Janssen, A.K. Jarmusch, L. Jiang, B.D. Kaehler, K. Bin Kang, C.R. Keefe, P. Keim, S.T. Kelley, D. Knights, I. Koester, T. Kosciolek, J. Kreps, M.G.I. Langille, J. Lee, R. Ley, Y.X. Liu, E. Loftfield, C. Lozupone, M. Maher, C. Marotz, B.D. Martin, D. McDonald, L.J. McIver, A. V. Melnik, J.L. Metcalf, S.C. Morgan, J.T. Morton, A.T. Naimey, J.A. NavasMolina, L.F. Nothias, S.B. Orchanian, T. Pearson, S.L. Peoples, D. Petras, M.L. Preuss, E. Pruesse, L.B. Rasmussen, A. Rivers, M.S. Robeson, P. Rosenthal, N. Segata, M. Shaffer, A. Shiffer, R. Sinha, S.J. Song, J.R. Spear, A.D. Swafford, L.R. Thompson, P.J. Torres, P. Trinh, A. Tripathi, P.J. Turnbaugh, S. Ul-Hasan, J.J.J. van der Hooft, F. Vargas, Y. Vázquez-Baeza, E. Vogtmann, M. von Hippel, W. Walters, Y. Wan, M. Wang, J. Warren, K.C. Weber, C.H.D. Williamson, A.D. Willis, Z.Z. Xu, J.R. Zaneveld, Y. Zhang, Q. Zhu, R. Knight, J.G. Caporaso, Reproducible, interactive, scalable and extensible microbiome data science using QIIME 2, Nat. Biotechnol. (2019). https://doi.org/10.1038/s41587-019-0209-9.

[23] B.J. Callahan, P.J. McMurdie, M.J. Rosen, A.W. Han, A.J.A. Johnson, S.P. Holmes, DADA2: High-resolution sample inference from Illumina amplicon data, Nat. Methods. (2016). https://doi.org/10.1038/nmeth.3869.

[24] N.A. Bokulich, B.D. Kaehler, J.R. Rideout, M. Dillon, E. Bolyen, R. Knight, G.A. Huttley, J. Gregory Caporaso, Optimizing taxonomic classification of marker-gene amplicon sequences with QIIME 2's q2-feature-classifier plugin, Microbiome. (2018). https://doi.org/10.1186/s40168-018-0470-z.

[25] D. McDonald, M.N. Price, J. Goodrich, E.P. Nawrocki, T.Z. Desantis, A. Probst, G.L. Andersen, R. Knight, P. Hugenholtz, An improved Greengenes taxonomy with explicit ranks for ecological and evolutionary analyses of bacteria and archaea, ISME J. (2012). https://doi.org/10.1038/ismej.2011.139.

[26] T. Rognes, T. Flouri, B. Nichols, C. Quince, F. Mahé, VSEARCH: A versatile open source tool for metagenomics, PeerJ. (2016). https://doi.org/10.7717/peerj.2584.

[27] M.G.I. Langille, J. Zaneveld, J.G. Caporaso, D. McDonald, D. Knights, J.A. Reyes, J.C. Clemente, D.E. Burkepile, R.L. Vega Thurber, R. Knight, R.G. Beiko, C. Huttenhower, Predictive functional profiling of microbial communities using 16S rRNA marker gene sequences, Nat. Biotechnol. (2013). https://doi.org/10.1038/nbt.2676.

[28] J.M. Poret, F. Souza-Smith, S.J. Marcell, D.A. Gaudet, T.H. Tzeng, H.D. Braymer, L.M. Harrison-Bernard, S.D. Primeaux, High fat diet consumption differentially affects adipose tissue inflammation and adipocyte size in obesity-prone and obesity-resistant rats, Int. J. Obes. (2018). https://doi.org/10.1038/ijo.2017.280. 
[29] C.B. De La Serre, C.L. Ellis, J. Lee, A.L. Hartman, J.C. Rutledge, H.E. Raybould, Propensity to high-fat diet-induced obesity in rats is associated with changes in the gut microbiota and gut inflammation, Am. J. Physiol. - Gastrointest. Liver Physiol. (2010). https://doi.org/10.1152/ajpgi.00098.2010.

[30] B.A. Petriz, A.P. Castro, J.A. Almeida, C.P.C. Gomes, G.R. Fernandes, R.H. Kruger, R.W. Pereira, O.L. Franco, Exercise induction of gut microbiota modifications in obese, non-obese and hypertensive rats, BMC Genomics. (2014). https://doi.org/10.1186/1471-2164-15-511.

[31] C.M. Stenkamp-Strahm, Y.E.A. Nyavor, A.J. Kappmeyer, S. Horton, M. Gericke, O.B. Balemba, Prolonged high fat diet ingestion, obesity, and type 2 diabetes symptoms correlate with phenotypic plasticity in myenteric neurons and nerve damage in the mouse duodenum, Cell Tissue Res. (2015). https://doi.org/10.1007/s00441-015-2132-9.

[32] Ibrahim KS, Biochemical Interactions Between the Gut Microbiome and Host In Obesity/Type II Diabetes, Glasgow Caledonian University, 2017.

[33] J.T. Morton, J. Sanders, R.A. Quinn, D. McDonald, A. Gonzalez, Y. Vázquez-Baeza, J.A. Navas-Molina, S.J. Song, J.L. Metcalf, E.R. Hyde, M. Lladser, P.C. Dorrestein, R. Knight, Balance Trees Reveal Microbial Niche Differentiation, MSystems. (2017). https://doi.org/10.1128/msystems.00162-16.

[34] P. Gut, B. Baeza-Raja, O. Andersson, L. Hasenkamp, J. Hsiao, D. Hesselson, K. Akassoglou, E. Verdin, M.D. Hirschey, D.Y.R. Stainier, Whole-organism screening for gluconeogenesis identifies activators of fasting metabolism, Nat. Chem. Biol. (2013). https://doi.org/10.1038/nchembio.1136.

[35] B. Costa, C. Cavallini, E. Da Pozzo, S. Taliani, F. Da Settimo, C. Martini, The Anxiolytic Etifoxine Binds to TSPO Ro5-4864 Binding Site with Long Residence Time Showing a High Neurosteroidogenic Activity, ACS Chem. Neurosci. (2017). https://doi.org/10.1021/acschemneuro.7b00027.

[36] Y.M. Lin, H.Y. Sun, W.T. Chiu, H.C. Su, Y.C. Chien, H.A. Chang, L.W. Chong, H.C. Chang, K.C. Young, C.H. Bai, C.W. Tsao, Etifoxine, a TSPO Ligand, Worsens Hepatitis C-Related Insulin Resistance but Relieves Lipid Accumulation, Biomed Res. Int. (2019). https://doi.org/10.1155/2019/3102414.

[37] M. Ouimet, T.J. Barrett, E.A. Fisher, HDL and reverse cholesterol transport: Basic mechanisms and their roles in vascular health and disease, Circ. Res. (2019). https://doi.org/10.1161/CIRCRESAHA.119.312617.

[38] J.M.W. Taylor, A.M. Allen, A. Graham, Targeting mitochondrial 18 kDa translocator protein (TSPO) regulates macrophage cholesterol efflux and lipid phenotype, Clin. Sci. (2014). 
https://doi.org/10.1042/CS20140047.

[39] L. Biswas, F. Farhan, J. Reilly, C. Bartholomew, X. Shu, TSPO ligands promote cholesterol efflux and suppress oxidative stress and inflammation in choroidal endothelial cells, Int. J. Mol. Sci. (2018). https://doi.org/10.3390/ijms19123740.

[40] A.M. Mowat, W.W. Agace, Regional specialization within the intestinal immune system, Nat. Rev. Immunol. (2014). https://doi.org/10.1038/nri3738.

[41] H. Liu, J. Wang, T. He, S. Becker, G. Zhang, D. Li, X. Ma, Butyrate: A double-edged sword for health?, Adv. Nutr. (2018). https://doi.org/10.1093/advances/nmx009.

[42] J.F. Sicard, G. Le Bihan, P. Vogeleer, M. Jacques, J. Harel, Interactions of intestinal bacteria with components of the intestinal mucus, Front. Cell. Infect. Microbiol. (2017). https://doi.org/10.3389/fcimb.2017.00387.

[43] R.B. Canani, M. Di Costanzo, L. Leone, M. Pedata, R. Meli, A. Calignano, Potential beneficial effects of butyrate in intestinal and extraintestinal diseases, World J. Gastroenterol. (2011). https://doi.org/10.3748/wjg.v17.i12.1519.

[44] C.C. Evans, K.J. LePard, J.W. Kwak, M.C. Stancukas, S. Laskowski, J. Dougherty, L. Moulton, A. Glawe, Y. Wang, V. Leone, D.A. Antonopoulos, D. Smith, E.B. Chang, M.J. Ciancio, Exercise prevents weight gain and alters the gut microbiota in a mouse model of high fat diet-induced obesity, PLoS One. (2014). https://doi.org/10.1371/journal.pone.0092193.

[45] L.J. Cohen, D. Esterhazy, S.H. Kim, C. Lemetre, R.R. Aguilar, E.A. Gordon, A.J. Pickard, J.R. Cross, A.B. Emiliano, S.M. Han, J. Chu, X. Vila-Farres, J. Kaplitt, A. Rogoz, P.Y. Calle, C. Hunter, J.K. Bitok, S.F. Brady, Commensal bacteria make GPCR ligands that mimic human signalling molecules, Nature. (2017). https://doi.org/10.1038/nature23874.

[46] T. Schulze, S. Golfier, C. Tabeling, K. Rab̈el, M.H. Gräler, M. Witzenrath, M. Lipp, Sphingosine-1-phospate receptor 4 (S1P 4) deficiency profoundly affects dendritic cell function and T H17-cell differentiation in a murine model, FASEB J. (2011). https://doi.org/10.1096/fj.10-179028.

[47] J. Bishara, R. Farah, J. Mograbi, W. Khalaila, O. Abu-Elheja, M. Mahamid, W. Nseir, Obesity as a risk factor for Clostridium difficile infection, Clin. Infect. Dis. (2013). https://doi.org/10.1093/cid/cit280.

[48] J. Leung, B. Burke, D. Ford, G. Garvin, C. Korn, C. Sulis, N. Bhadelia, Possible association between obesity and Clostridium difficile infection, Emerg. Infect. Dis. (2013). https://doi.org/10.3201/eid1911.130618.

[49] T. Nakatsuji, D. chu C. Tang, L. Zhang, R.L. Gallo, C.M. Huang, Propionibacterium acnes 
camp factor and host acid sphingomyelinase contribute to bacterial virulence: Potential targets for inflammatory acne treatment, PLoS One. (2011). https://doi.org/10.1371/journal.pone.0014797.

[50] O. Slaby, A. McDowell, H. Brüggemann, A. Raz, S. Demir-Deviren, T. Freemont, P. Lambert, M.N. Capoor, Is IL-1 $\beta$ further evidence for the role of Propionibacterium acnes in degenerative disc disease? Lessons from the study of the inflammatory skin condition acne vulgaris, Front. Cell. Infect. Microbiol. (2018). https://doi.org/10.3389/fcimb.2018.00272.

[51] B.R. Vowels, S. Yang, J.J. Leyden, Induction of proinflammatory cytokines by a soluble factor of Propionibacterium acnes: Implications for chronic inflammatory acne, Infect. Immun. (1995).

[52] G. Clarke, K. V. Sandhu, B.T. Griffin, T.G. Dinan, J.F. Cryan, N.P. Hyland, Gut reactions: Breaking down xenobiotic-microbiome interactions, Pharmacol. Rev. (2019). https://doi.org/10.1124/pr.118.015768.

[53] K. Nirmalkar, S. Murugesan, M.L. Pizano-Zárate, L.E. Villalobos-Flores, C. García-González, R.M. Morales-Hernández, J.A. Nuñez-Hernández, F. Hernández-Quiroz, M.D.S. RomeroFigueroa, C. Hernández-Guerrero, C. Hoyo-Vadillo, J. García-Mena, Gut microbiota and endothelial dysfunction markers in obese Mexican children and adolescents, Nutrients. (2018). https://doi.org/10.3390/nu10122009.

[54] M. Martinez-Gil, K.G.K. Goh, E. Rackaityte, C. Sakamoto, B. Audrain, D.G. Moriel, M. Totsika, J.M. Ghigo, M.A. Schembri, C. Beloin, YeeJ is an inverse autotransporter from Escherichia coli that binds to peptidoglycan and promotes biofilm formation, Sci. Rep. (2017). https://doi.org/10.1038/s41598-017-10902-0.

[55] M.B. Miller, B.L. Bassler, Quorum Sensing in Bacteria, Annu. Rev. Microbiol. (2001). https://doi.org/10.1146/annurev.micro.55.1.165.

[56] J.B. Kaper, V. Sperandio, Bacterial cell-to-cell signaling in the gastrointestinal tract, Infect. Immun. (2005). https://doi.org/10.1128/IAI.73.6.3197-3209.2005.

[57] A.C.C. Kao, S. Spitzer, D.C. Anthony, B. Lennox, P.W.J. Burnet, Prebiotic attenuation of olanzapine-induced weight gain in rats: Analysis of central and peripheral biomarkers and gut microbiota, Transl. Psychiatry. (2018). https://doi.org/10.1038/s41398-018-0116-8.

[58] M.A. Jackson, S. Verdi, M.E. Maxan, C.M. Shin, J. Zierer, R.C.E. Bowyer, T. Martin, F.M.K. Williams, C. Menni, J.T. Bell, T.D. Spector, C.J. Steves, Gut microbiota associations with common diseases and prescription medications in a population-based cohort, Nat. Commun. (2018). https://doi.org/10.1038/s41467-018-05184-7. 
681 [59] C.G. Buffie, I. Jarchum, M. Equinda, L. Lipuma, A. Gobourne, A. Viale, C. Ubeda, J. Xavier, E.G. Pamer, Profound alterations of intestinal microbiota following a single dose of clindamycin results in sustained susceptibility to Clostridium difficile-induced colitis, Infect. Immun. (2012). https://doi.org/10.1128/IAI.05496-11.

[60] J.M. Ridlon, D.J. Kang, P.B. Hylemon, J.S. Bajaj, Bile acids and the gut microbiome, Curr. Opin. Gastroenterol. (2014). https://doi.org/10.1097/MOG.0000000000000057.

[61] F.L. Sauvage, N. Picard, F. Saint-Marcoux, J.M. Gaulier, G. Lachâtre, P. Marquet, General unknown screening procedure for the characterization of human drug metabolites in forensic toxicology: Applications and constraints, J. Sep. Sci. (2009). https://doi.org/10.1002/jssc.200900092.

[62] K. Gloux, J. Anba-Mondoloni, Unique ß-glucuronidase locus in gut microbiomes of Crohn's disease patients and unaffected first-degree relatives, PLoS One. (2016). https://doi.org/10.1371/journal.pone.0148291. 


\section{Legends for Figures}

Figure 1: Effects of high-fat diet and subsequent administration of etifoxine on body weight, serum lipids and hepatic transcripts

Weight gain by mice on a control or high-fat diet during the initial phase of the experiment (a) and subsequent phase when etifoxine was administered to a group of the HFD animals (b). Serum total cholesterol (mg/dL) (c) and total triglyceride (mg/dL) (d) at the end of the experiment and relative expression of hepatic transcripts of cholesterol related genes (e) and inflammatory cytokines (d) in Control Diet, CD; High-fat diet, HFD; and High-fat diet + etifoxine, HFD+E (n= 6/group) One-way ANOVA followed by Tukey's multiple comparisons test a, b, c and d; Kruskal-Wallis followed by Dunn's multiple comparisons test e and f; and d $* \&^{\#} \mathrm{p}<0.05 . * * \&{ }^{\# \#} \mathrm{p}<0.01$, and $* * * \&^{\# \# \#} \mathrm{p}<0.001$.

Figure 2: Bacterial taxonomy of the three experimental groups.

Bacterial abundance (mean \%, $n=6$ /group) of colon samples at level of phyla (a), the ratio of Firmicutes/ Bacteroides (b) and at the level of species (c) of the gut metagenome. Keys; Control Diet, CD; High-fat diet, HFD; and High-fat diet + etifoxine, HFD+E. Kruskal-Wallis a and c; One-way ANOVA b; * $\&^{\#} \mathrm{p}<0.05 . * * \&^{\# \#} \mathrm{p}<0.01$, and ${ }^{* * *} \&^{\# \# \#} \mathrm{p}<0.001$.

Figure 3: Bacterial $\alpha$ - and $\beta$-diversity and differential abundance of taxa based on balances metrics in bacterial communities among the three groups

The Kruskal-Wallis test was used ( $n=6$ /group) to determine the relationship of $\alpha$-diversity metrics between the microbiome of the mice groups; observed_otus (a) and chao1 (b). Differences of $\beta$-diversity in bacterial communities between groups were conducted by 3D PCoA with Bray Curtis (c), and weighted unifrac (d). Differential abundance of taxa based on balances metrics between the three groups; log ratio of balance (e), and detail of taxonomy (f). Keys; Control Diet, CD; High-fat diet, HFD; and High-fat diet + etifoxine, HFD+E. Blue= CD; Red= HFD and Green=HFD+E.

Figure 4: PICRUSt analysis of the functional metabolic potential of the microbiome of each group

The Kruskal-Wallis test followed by Dunn's multiple comparisons test ( $n=6$ /group), pair-wise comparison, was used to estimate the significant differences of relative abundance of all of 
724 KEGG Pathway at level 3. Significant differences of these pathways were found in 39 pathways $* \mathrm{p}<0.05$ and $* * \mathrm{p}<0.01$.

Figure 5: Metagenomic analysis of butanoate metabolism [PATH: ko00650].

Imputed activities of orthologous enzymes for each group were evaluated by PICRUSt (a). The Kruskal-Wallis followed by Dunn's multiple comparisons test was used to estimate the significance between groups (\# \& * $\mathrm{p}<0.05$ ). Metagenomic contributions of organisms to butanoate formation by butyrate kinase [EC:2.7.2.7]) (b) and phosphate butyryl-transferase [EC:2.3.1.19]) (c). Keys; Control Diet, CD; High-fat diet, HFD; and High-fat diet + etifoxine, HFD+E.

Figure 6: Metagenomic analysis of lipid metabolism.

Imputed activities of lipid metabolism for each group (n=6/group) were evaluated at level 2 by PICRUSt (a) and of orthologous enzymes for ketone body metabolism [PATH:ko00072] at level 3 (b). One-way ANOVA followed by Tukey's multiple comparisons test for a and the Kruskal-Wallis followed by Dunn's multiple comparisons test for b was used to estimate the significance between groups (\# \& * p $<0.05$ ). Keys; Control Diet, CD; High-fat diet, HFD; and High-fat diet + etifoxine, HFD+E.

Figure 7: Expression of imputed bacterial enzyme contributions of the sphingolipid pathway

The pathway of sphingolipid metabolism [PATH: ko00600] is shown (a) along with imputed metabolic contributions of organisms in the three groups ( $n=6$ /group) to individual reactions (b).

Figure 8: Metagenomic analysis of the production of virulence factors and bile acids.

745 Imputed contributions from organisms to the production of toxins (a), of epithelial cell 746 invasion [PATH: ko05100] (b), of lipopolysaccharide (LPS) synthesis (c) and to the 747 biosynthesis of secondary bile acids [PATH: ko00121] (d) were evaluated by PICRUSt. 748 Kruskal-Wallis followed by Dunn's multiple comparisons test ( $n=6 /$ group) was used to 749 estimate the differences between groups. Keys; Control Diet, CD; High-fat diet, HFD; and 750 High-fat diet + etifoxine, HFD+E. 
752 Figure 9: Comparison of groups in imputed levels of drug metabolism - (other enzymes)

1753 [PATH:ko00983]

\section{Legends for Tables}

Table 1: Primers used for qRT-PCR for hepatic transcript analysis

Table 1: Total counts for raw and trimmed reads

Basic statistics for sequencing results of the 16S rRNA gene fragments. 
Graphical Abstract (for review)

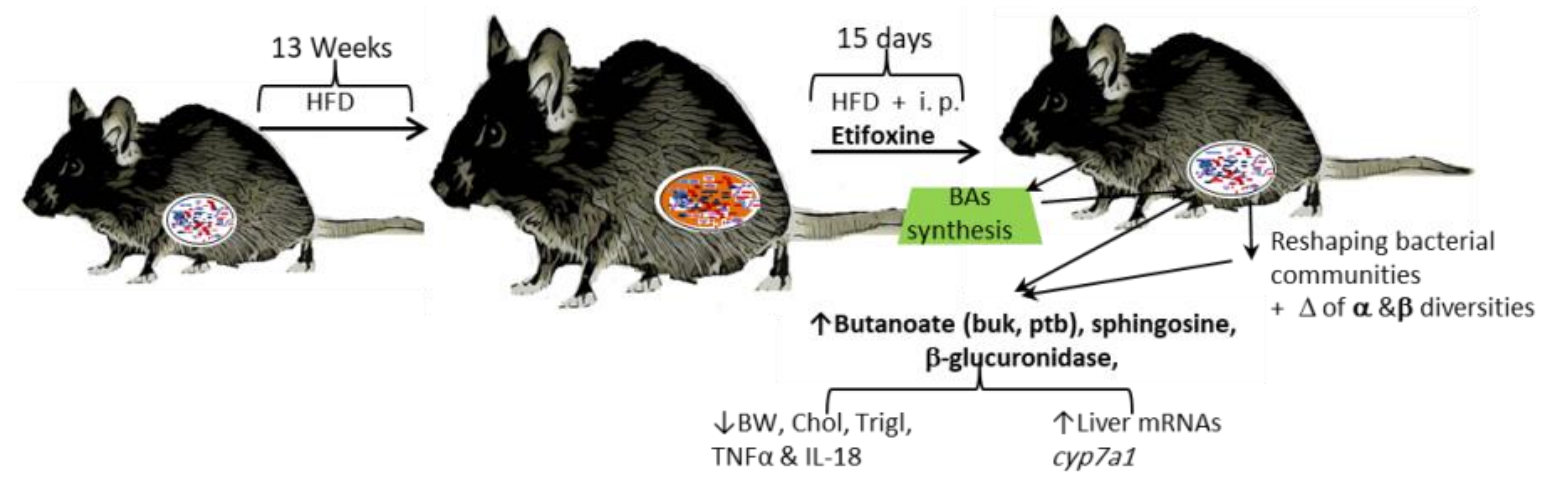

Graphic abstract 


\section{Author's contributions}

XS designed the study; LB and KSI conducted the experiments; JAC conducted the bioinformatics; JAC, LB and KSI analysed the data and wrote the manuscript; XS, KSI, JS and JAC reviewed the manuscript. 
Table 1: Primers used for qRT-PCR for hepatic transcript analysis

\begin{tabular}{|l|l|l|}
\hline Gene & Forward Primer (5' $\left.{ }^{\prime} \mathbf{3}^{\prime}\right)$ & Reverse Primer (3'-5') \\
\hline$\beta$-actin & CTCTAGACTTCGAGCAGGAGAT & CAGCACTGTGTTGGCATAGA \\
\hline IL-1 $\beta$ & CAGGCAGGCAGTATCACTCA & AGCTCATATGGGTCCGACAG \\
\hline TNF- $\alpha$ & ACGTGGAACTGGCAGAAGAG & AGGGTCTGGGCCATAGAACT \\
\hline IL-18 & GAAGAAAATGGAGACCTGG & 'TTCACAGAGAGGGTCACA \\
\hline LXRa & CCCTAGCCTTTCCCCAAATTGC & CGGAAGAATCCCTTGCAACC \\
\hline abca1 & AGTTTCGGTATGGCGGGTTT & AGCATGCCAGCCCTTGTTAT \\
\hline abcg1 & ACCTACCACAACCCAGCAGACTTT & GGTGCCAAAGAAACGGGTTCACAT \\
\hline cyp27a1 & GCCTTGCACAAGGAAGTGACT & CGCAGGGTCTCCTTAATCACA \\
\hline cyp7a1 & TGGGCATCTCAAGCAAACAC & TCATTGCTTCAGGGCTCCTG \\
\hline
\end{tabular}


Table 2: Total counts for raw and trimmed reads

\begin{tabular}{|c|c|c|c|c|c|c|}
\hline $\begin{array}{c}\text { Sample } \\
\text { Name }\end{array}$ & $\begin{array}{c}\text { Raw total } \\
\text { reads }\end{array}$ & $\begin{array}{c}\text { Raw read } \\
\text { pairs }\end{array}$ & $\begin{array}{c}\text { Adapter } \\
\text { clipped total }\end{array}$ & $\begin{array}{c}\text { Adapter } \\
\text { dipped }\end{array}$ & $\begin{array}{c}\text { Primer clipped } \\
\text { total reads }\end{array}$ & $\begin{array}{c}\text { Primer clipped } \\
\text { read pairs }\end{array}$ \\
\hline CD 1 & 223048 & 111524 & 223048 & 111524 & 220698 & 110349 \\
\hline CD 2 & 217254 & 108627 & 217248 & 108624 & 214374 & 107187 \\
\hline CD 3 & 207266 & 103633 & 207266 & 103633 & 204949 & 102474 \\
\hline CD 4 & 235744 & 117872 & 235734 & 117867 & 233198 & 116599 \\
\hline CD 5 & 151762 & 75881 & 151762 & 75881 & 149742 & 74871 \\
\hline CD 6 & 206152 & 103076 & 206150 & 103075 & 202560 & 101280 \\
\hline HFD 1 & 128016 & 64008 & 127980 & 63990 & 125876 & 62938 \\
\hline HFD 2 & 64408 & 32204 & 64396 & 32198 & 63312 & 31656 \\
\hline HFD 3 & 188408 & 94204 & 188396 & 94198 & 185772 & 92886 \\
\hline HFD 4 & 196682 & 98341 & 196678 & 98339 & 191436 & 95718 \\
\hline HFD 5 & 137236 & 68618 & 136832 & 68416 & 132098 & 66049 \\
\hline HFD 6 & 245610 & 122805 & 245600 & 122800 & 242728 & 121364 \\
\hline HFD+E 1 & 189798 & 94899 & 189792 & 94896 & 187580 & 93790 \\
\hline HFD+E 2 & 269894 & 134947 & 269810 & 134905 & 258506 & 129253 \\
\hline HFD+E 3 & 272564 & 136282 & 272560 & 136280 & 269330 & 134665 \\
\hline HFD+E 4 & 255722 & 112861 & 225722 & 112861 & 223344 & 111672 \\
\hline HFD+E 5 & 265004 & 132502 & 264912 & 132456 & 261238 & 130619 \\
\hline HFD+E 6 & 211918 & 105959 & 211914 & 105957 & 209224 & 104612 \\
\hline KeYS HFD & 2 Hig & & \\
\hline
\end{tabular}

Keys: HFD+E=High fat diet + etifoxine, HFD = High fat diet and CD = Control 

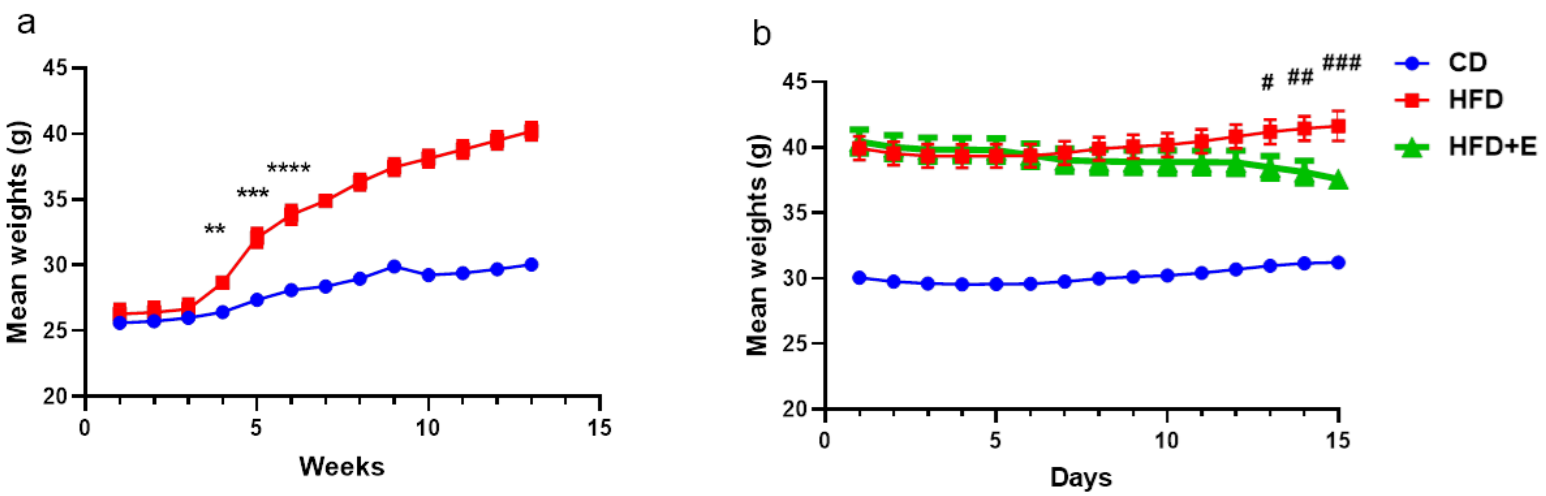

CD HFD HFD+E

C

d
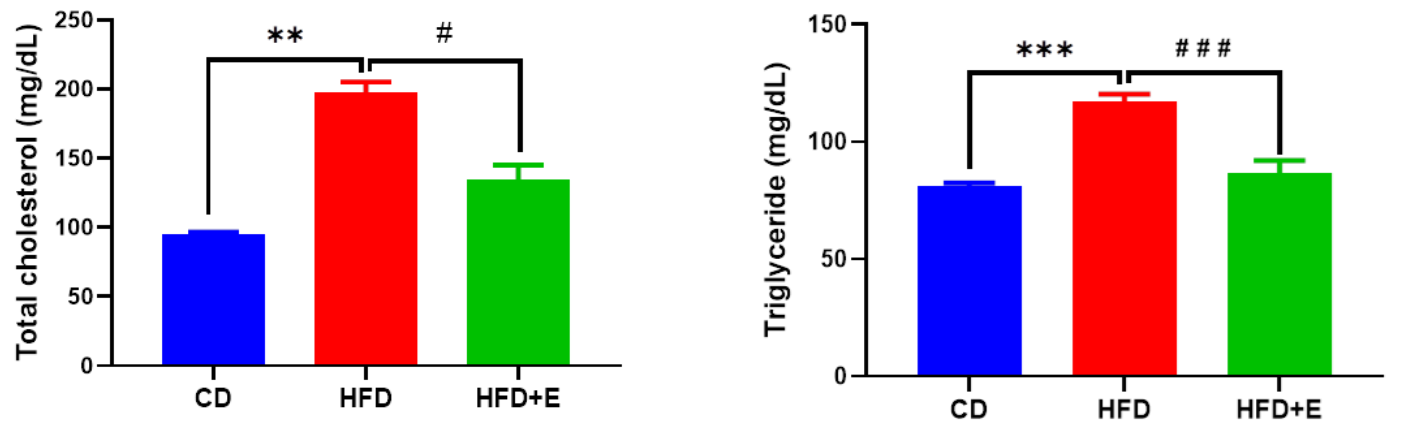

e
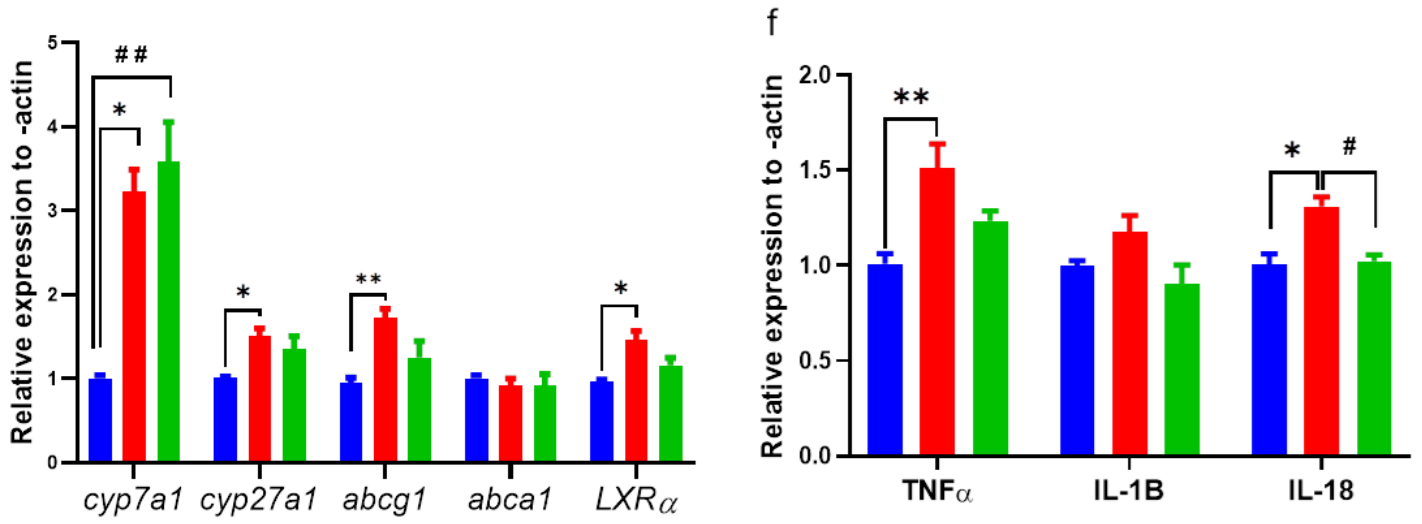

Figure 1 


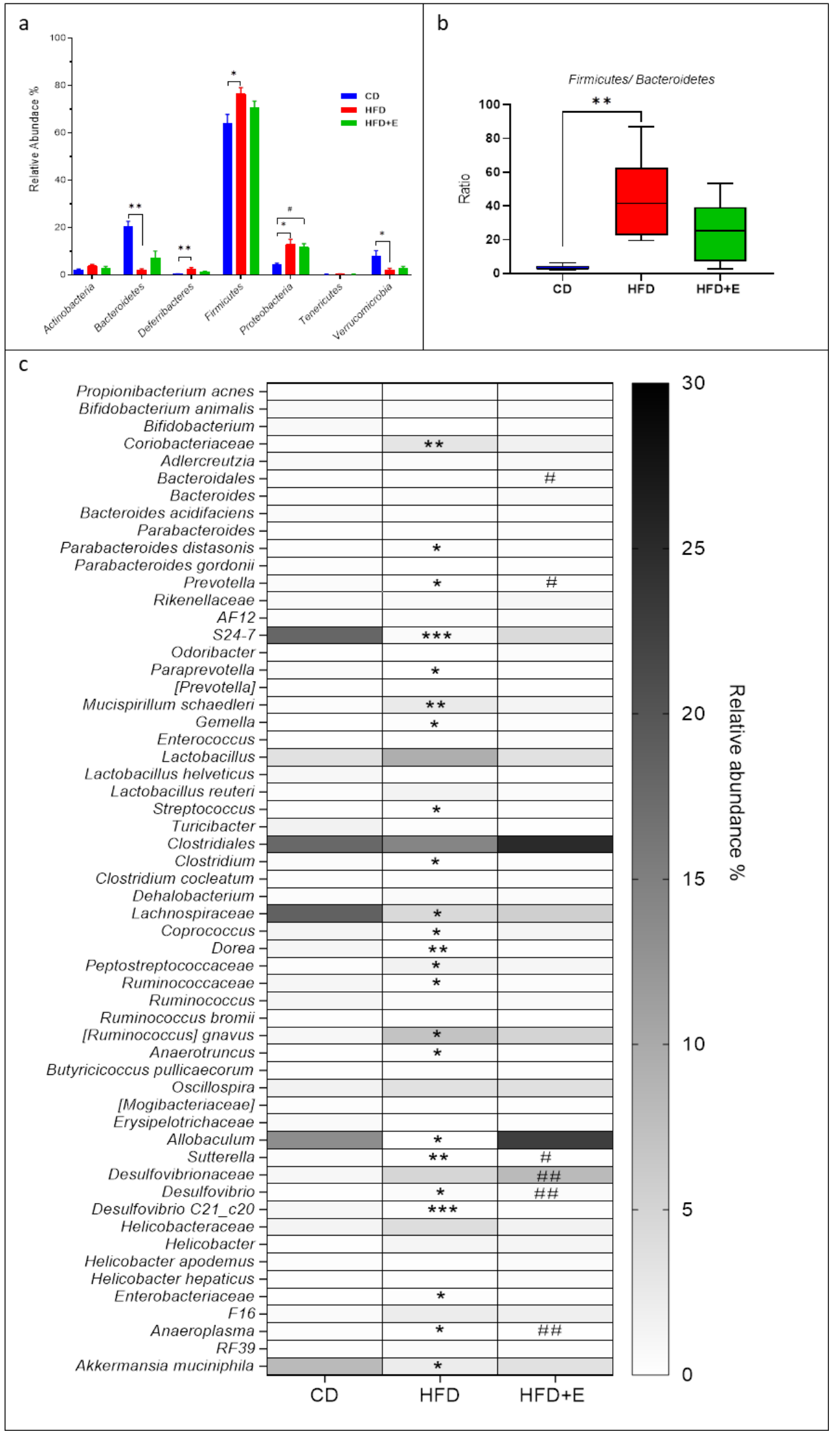

Figure 2 


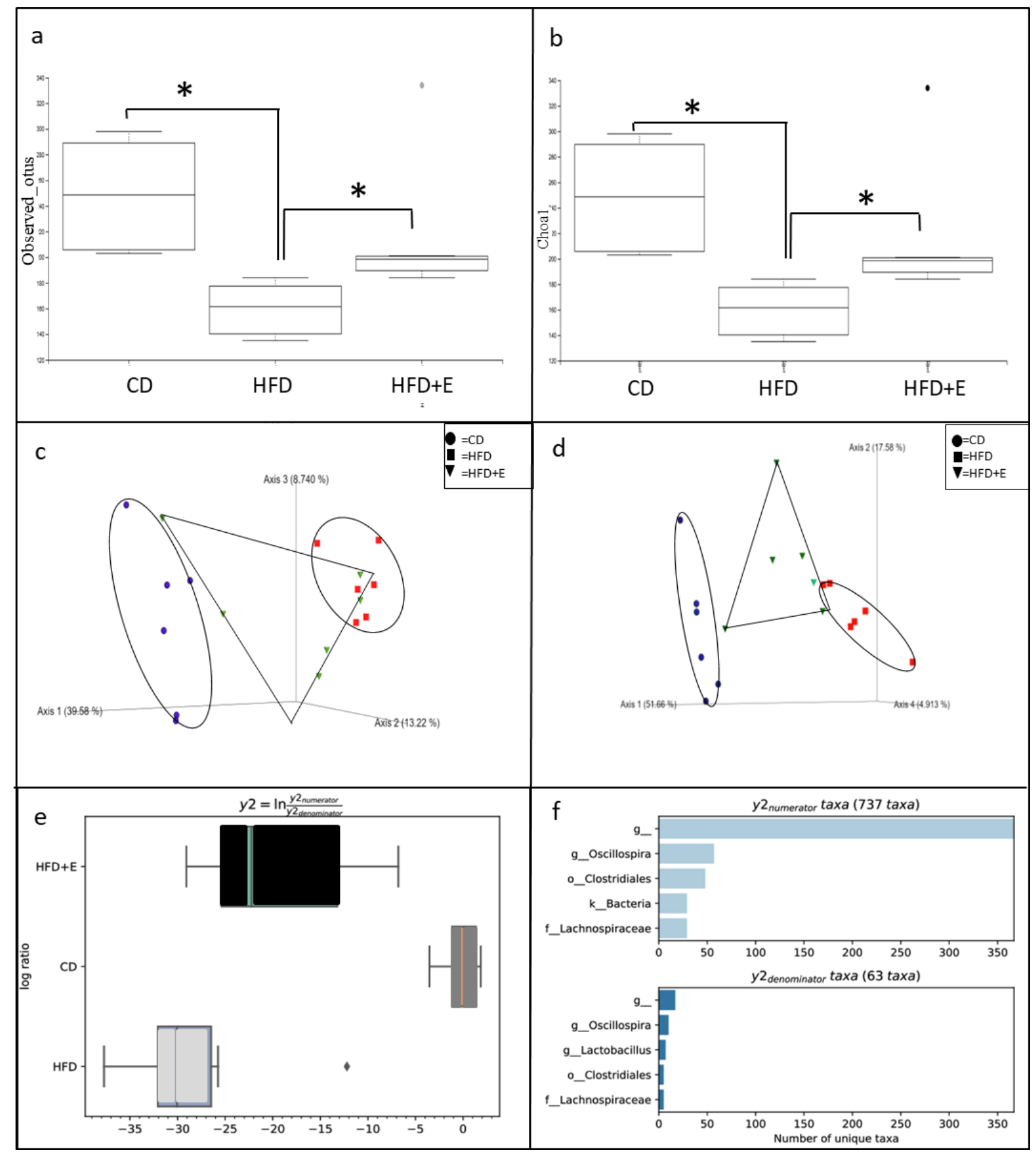

Figure 3 


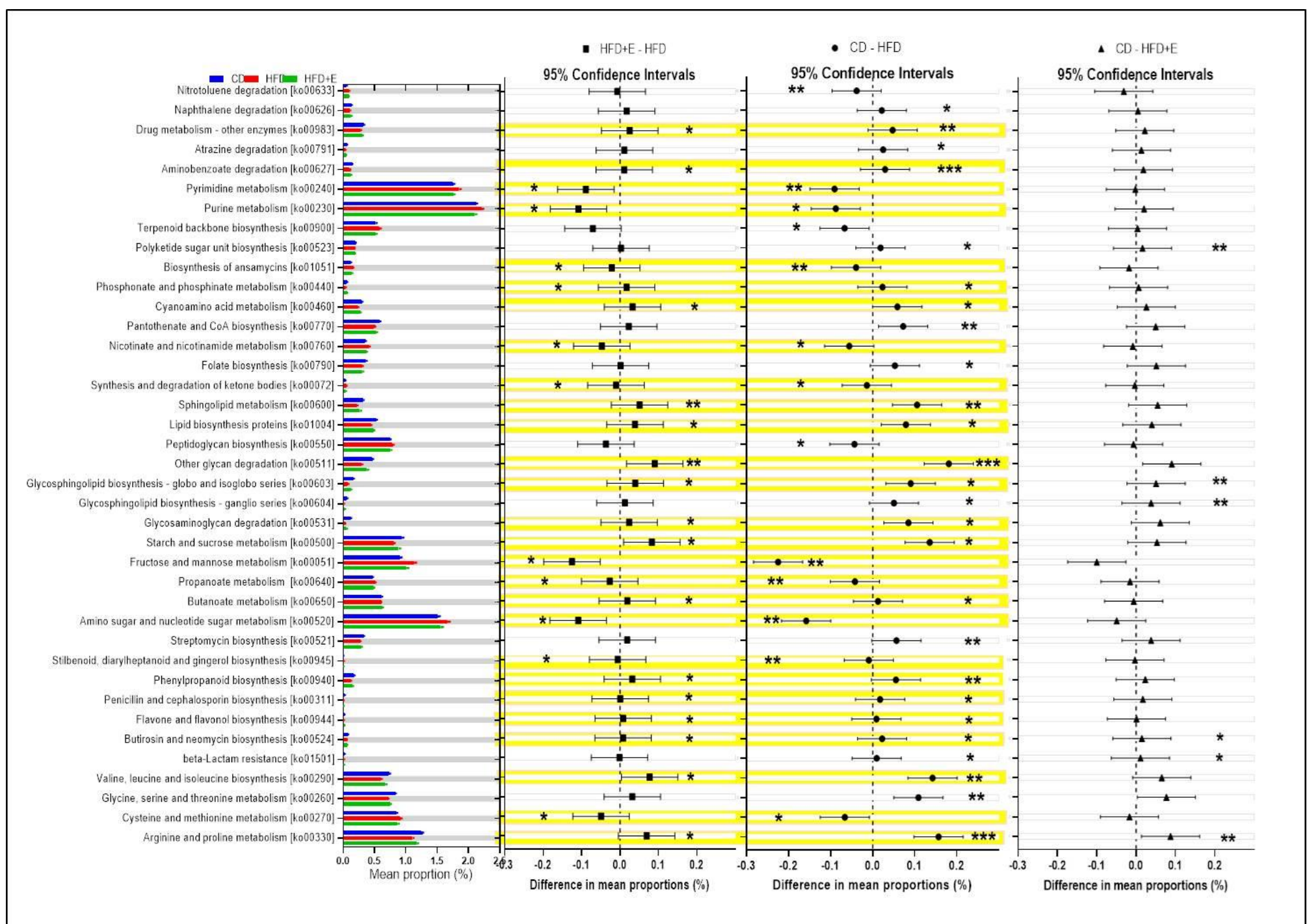

Figure 4 


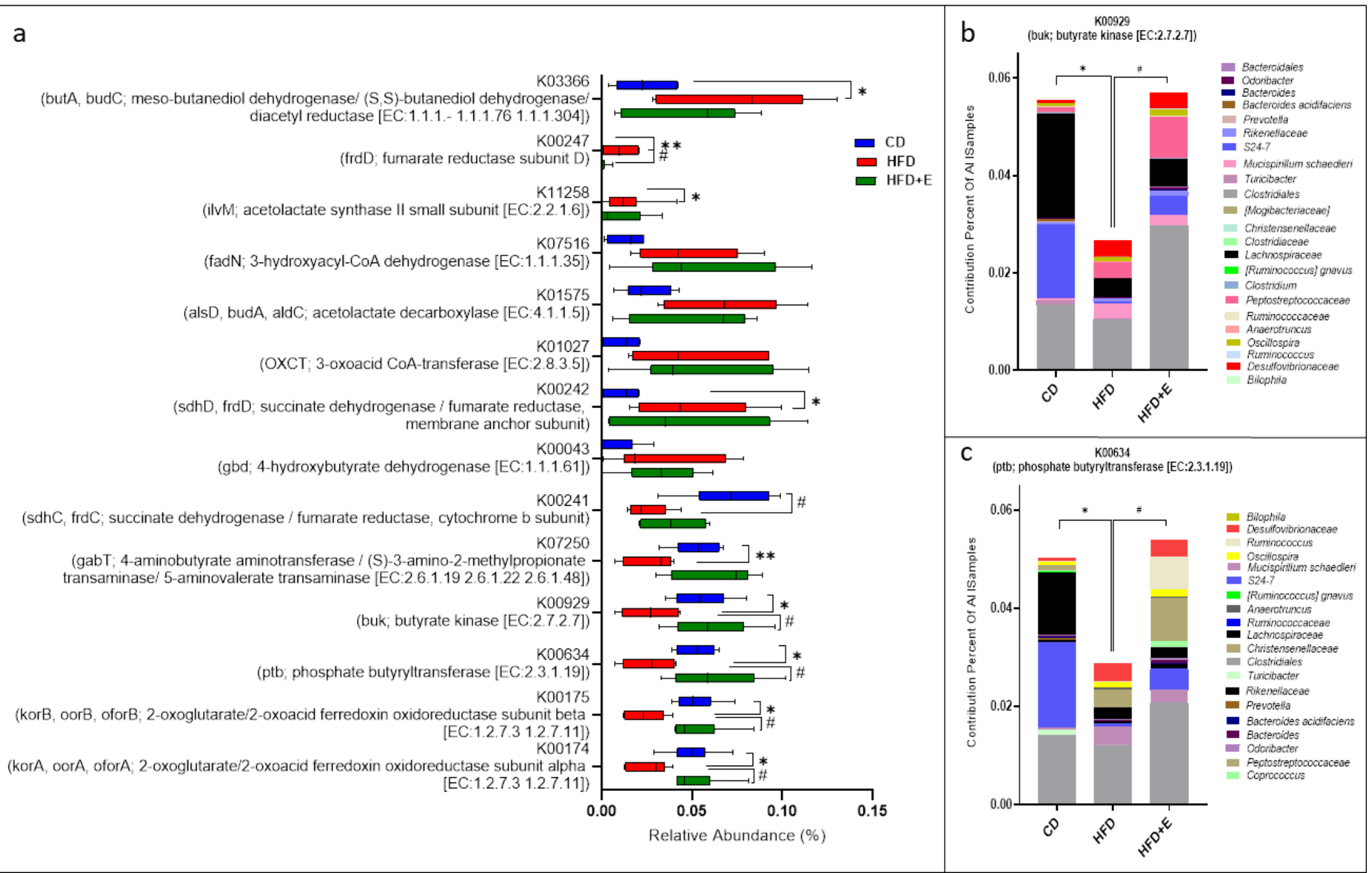

Figure 5 


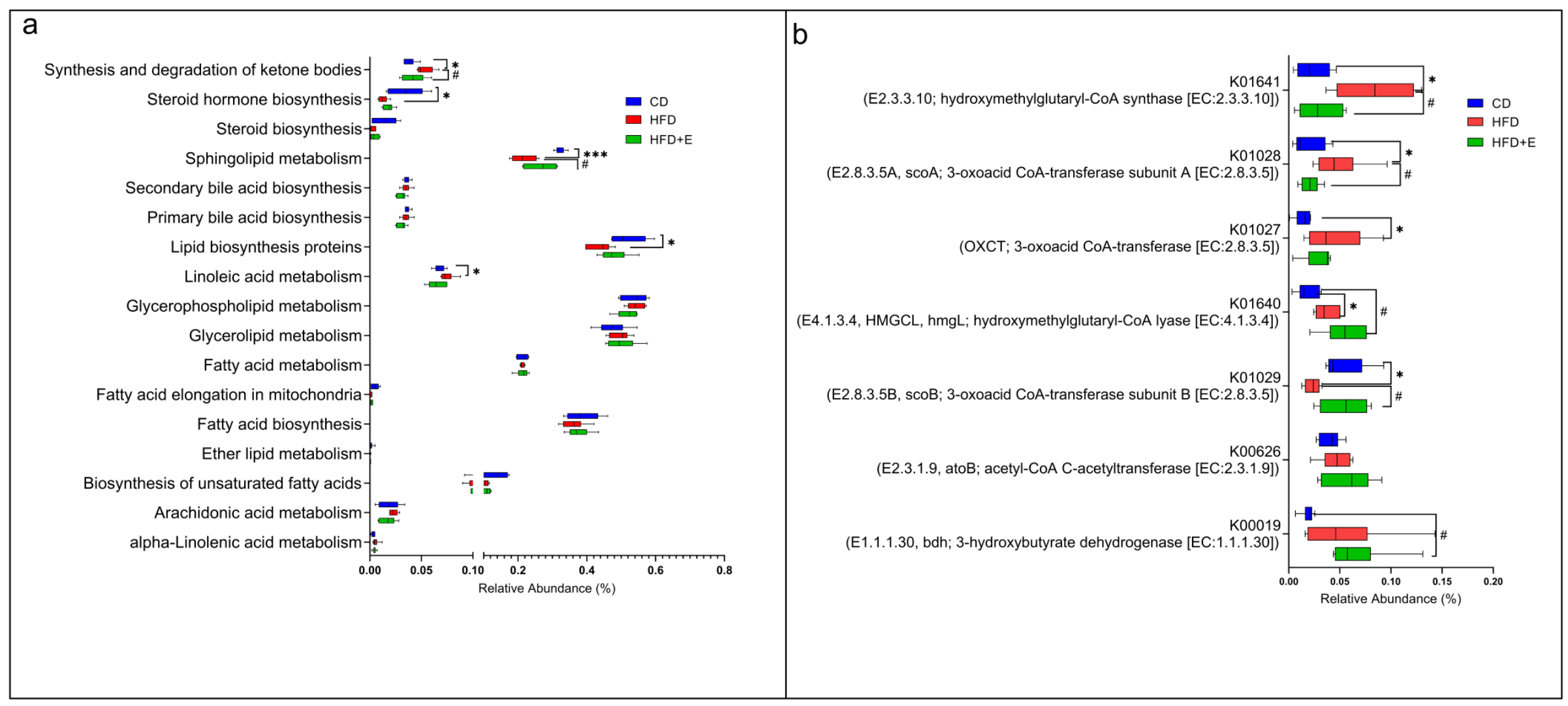

Figure 6 


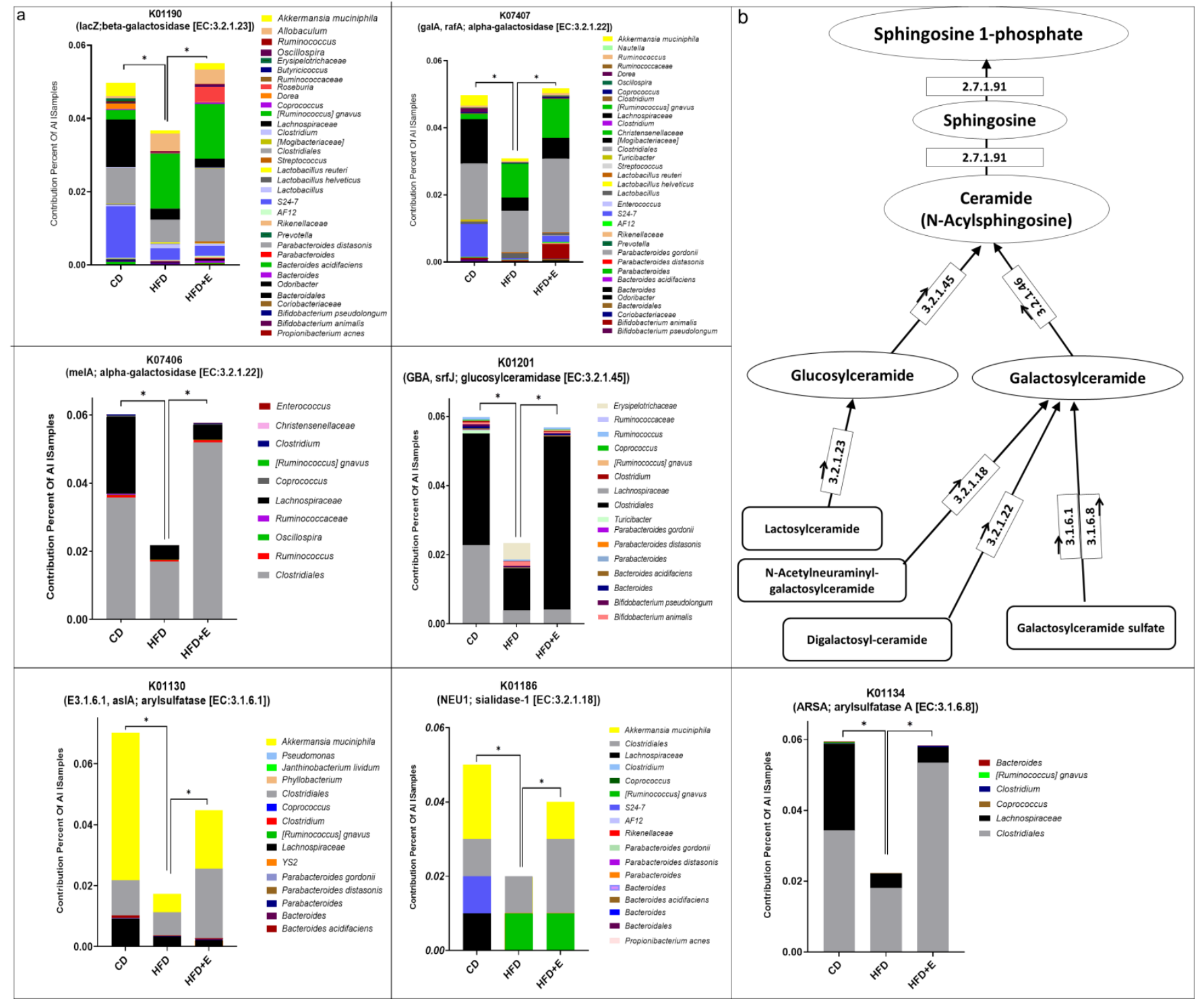

Figure 7 


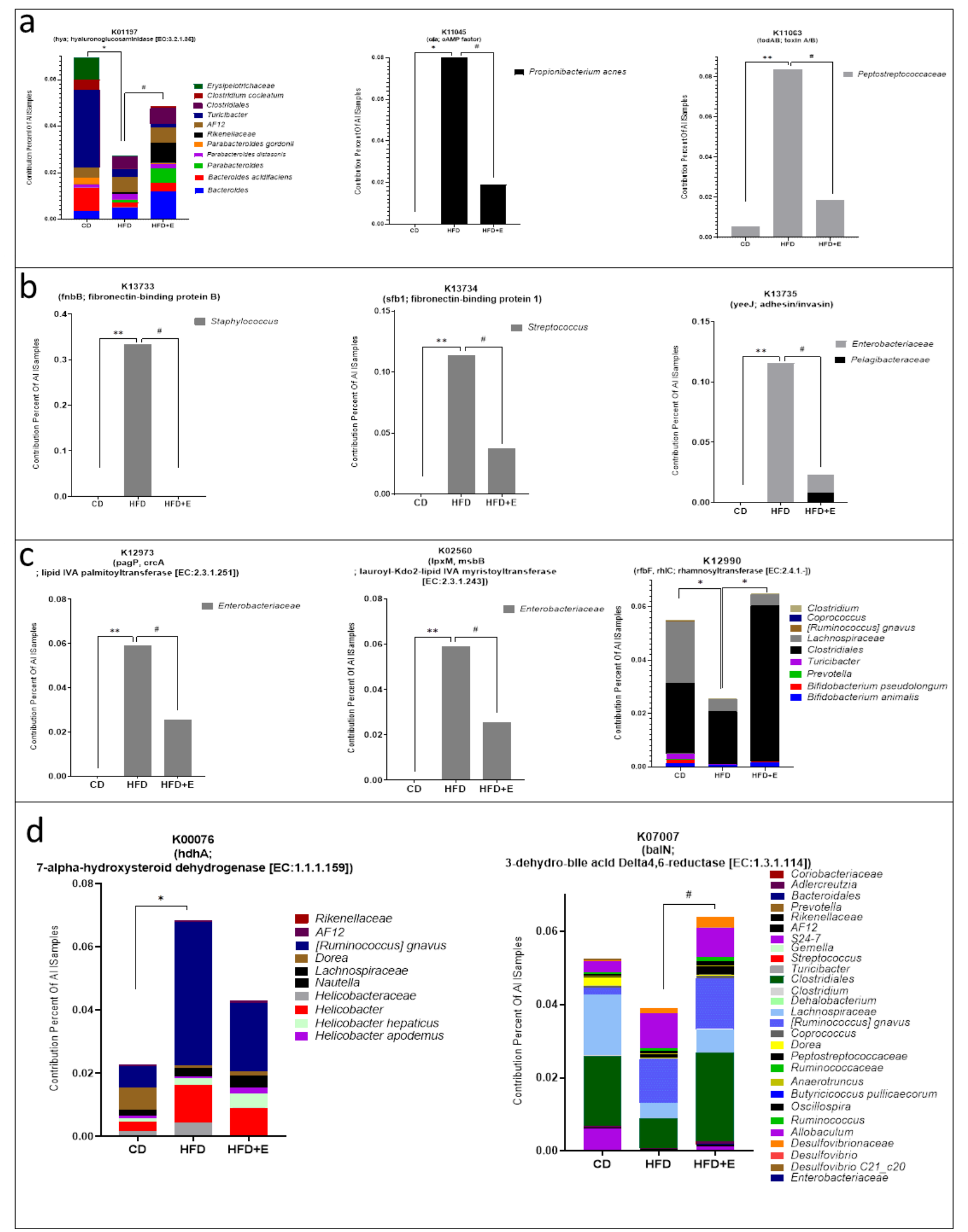

Figure 8 


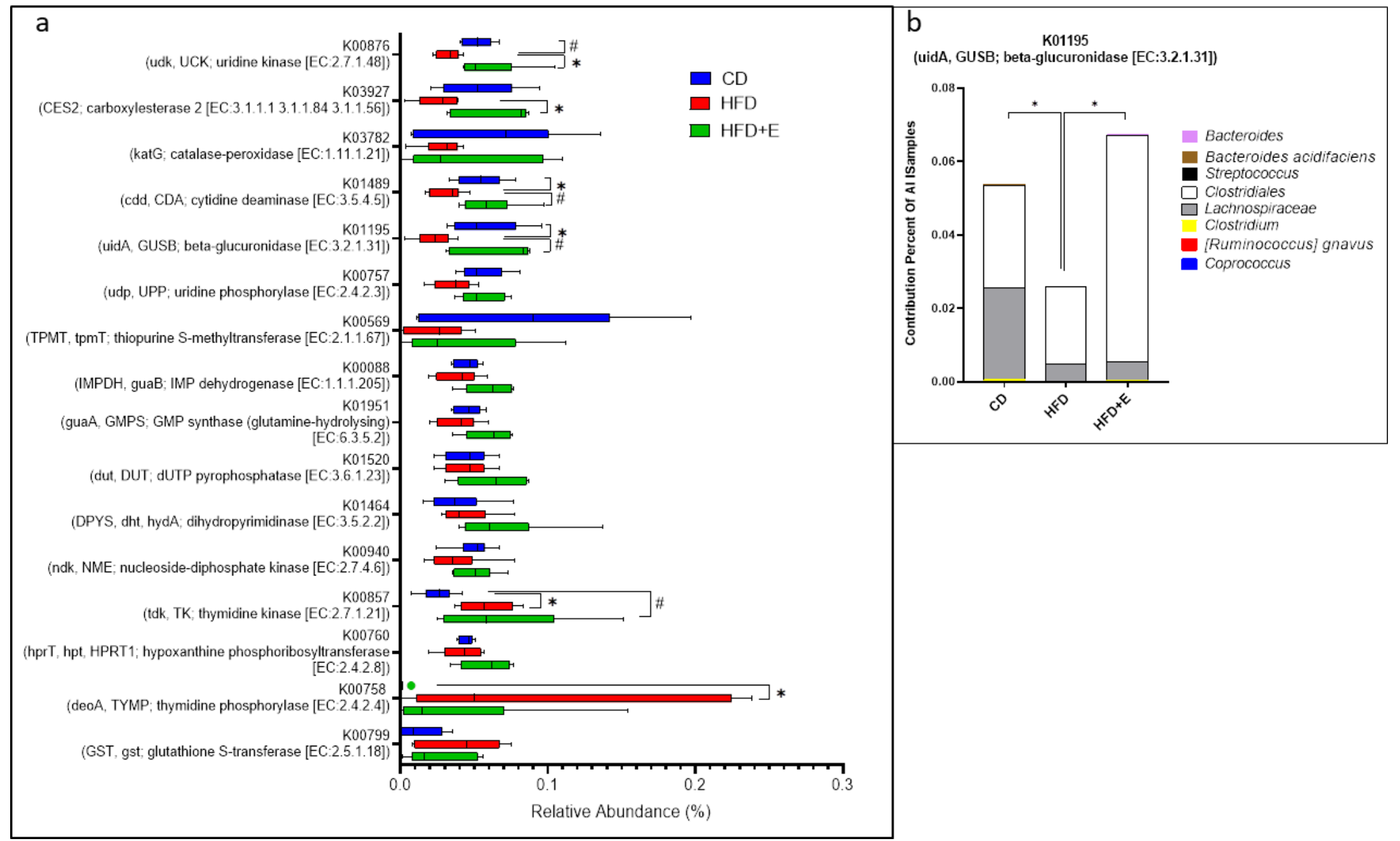

Figure 9 